Rodrigo Martins Porto

\title{
PAPEL DOS RECEPTORES NUCLEARES ATIVADOS POR PROLIFERADORES DE PEROXISSOMOS (PPAR) NA PERIODONTITE INDUZIDA EM RATOS
}

Tese apresentada ao programa de PósGraduação em Farmacologia do Instituto de Instituto de Ciências Biomédicas da Universidade de São Paulo, para obtenção do Título de Doutorado em Ciências. 


\author{
Rodrigo Martins Porto
}

\title{
PAPEL DOS RECEPTORES NUCLEARES ATIVADOS POR PROLIFERADORES DE PEROXISSOMOS (PPAR) NA PERIODONTITE INDUZIDA EM RATOS
}

\begin{abstract}
Tese apresentada ao programa de PósGraduação em Farmacologia do Instituto de Instituto de Ciências Biomédicas da Universidade de São Paulo, para obtenção do Título de Doutorado em Ciências.
\end{abstract}

Área de concentração: Farmacologia

Orientador : Prof. Dr. Marcelo N. Muscará

Versão original. 
DADOS DE CATALOGAÇÃO NA PUBLICAÇÃO (CIP)

Serviço de Biblioteca e Informação Biomédica do

Instituto de Ciências Biomédicas da Universidade de São Paulo

reprodução não autorizada pelo autor

Martins-Porto, Rodrigo.

Papel dos receptores nucleares ativados por proliferadores de peroxissomos (PPAR) na periodontite induzida em ratos /

Rodrigo Martins Porto. -- São Paulo, 2012.

Orientador: Prof. Dr. Marcelo Nicolas Muscara.

Tese (Doutorado) - Universidade de São Paulo. Instituto de Ciências Biomédicas. Departamento de Farmacologia. Área de concentração: Farmacologia. Linha de pesquisa: Inflamação

Versão do título para o inglês: Role of peroxisome proliferator activated nuclear receptor (PPAR) in induced periodontitis in rats.

1. Periodontite 2. Inflamação 3. PPAR 4. Metabolismo ósseo 5. Ratos I. Muscara, Prof. Dr. Marcelo Nicolas II. Universidade de São Paulo. Instituto de Ciências Biomédicas. Programa de PósGraduação em Farmacologia III. Título. 
Candidato(a): $\quad$ Rodrigo Martins Porto.

Título da Tese: $\quad$ Papel dos receptores nucleares ativados por proliferadores de peroxissomos (PPAR) na periodontite induzida em ratos.

Orientador(a): $\quad$ Prof. Dr. Marcelo Nicolas Muscara.

A Comissão Julgadora dos trabalhos de Defesa da Tese de Doutorado, em sessão pública realizada a .................., considerou

\section{( ) Aprovado(a) ( ) Reprovado(a)}

\begin{tabular}{|c|c|}
\hline Examinador(a): & $\begin{array}{l}\text { Assinatura: } \\
\text { Nome: ........ } \\
\text { Instituição: . }\end{array}$ \\
\hline Examinador(a): & $\begin{array}{l}\text { Assinatura: } \\
\text { Nome: ......... } \\
\text { Instituição: . }\end{array}$ \\
\hline Examinador(a): & $\begin{array}{l}\text { Assinatura: } \\
\text { Nome: ........ } \\
\text { Instituição: . }\end{array}$ \\
\hline Examinador(a): & $\begin{array}{l}\text { Assinatura: } \\
\text { Nome: ........ } \\
\text { Instituição: . }\end{array}$ \\
\hline Presidente: & $\begin{array}{l}\text { Assinatura: } \\
\text { Nome: ....... } \\
\text { Instituição: . }\end{array}$ \\
\hline
\end{tabular}




\section{UNIVERSIDADE DE SÃO PAULO INSTITUTO DE CIÊNCIAS BIOMÉDICAS}

Cidade Universitåria "Armando de Salles Oliveira"

Av. Prof. Lineu Prestes, 2415 - CEP. 05508-000 Săo Paulo, SP - Brasil

Telefone:(55) (011) 3091.7733 - telefax : (55) (011) 3091.7438

e-mail: cep@icb.usp.br

\section{Certificado}

Certificamos que o protocolo registrado sob $n^{\circ} 077$ nas fls. 33 do livro 2 para uso de animais em experimentação, sob a responsabilidade de Marcelo Nicolas Muscará, Coordenador(a) da Linha de Pesquisa "Papel do receptor nuclear gama ativado por proliferadores de peroxissomos (PPAR-gama) na periodontite induzida em ratos" do qual participou(aram) o(s) alunos Rodrigo Martins Porto, Paula Campi Locatelli de Almeida, Bruno Schneider Herrera, Aline Maia Dantas, Ana Alice dos Santos Dias, Alexandre Denadai Souza, Ana Augusta Varriano, Simone Marques Bolonnheis, Carly de Faria Coelho, 
Cristian César Carrari, Lidia Mitiko Yshii, Livia de Lucca Camargo, Juliano Fernandes de Oliveira, Juliana Florenzano, Ligia de Cássia Val, Livia Pimentel, Luciano Ramos, Rodrigo Labat Marcos e os pesquisadores Soraia Kátia P.Costa, Rodrigo Allvaro B.L.Martins, está de acordo com os Principios Éticos de Experimentação Animal adotado pelo Colégio Brasileiro de Experimentação Animal (COBEA) e foi aprovado pela COMISSÃO DE ÉTICA EM EXPERIMENTAÇÃO ANIMAL (CEEA) em 26.05.2006.

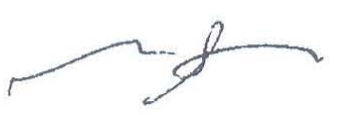

Profa. Dra. Marília C.L.Seelaender Coordenadora -CEEA - ICB/USP
São Paulo, 26 de maio de 2006.

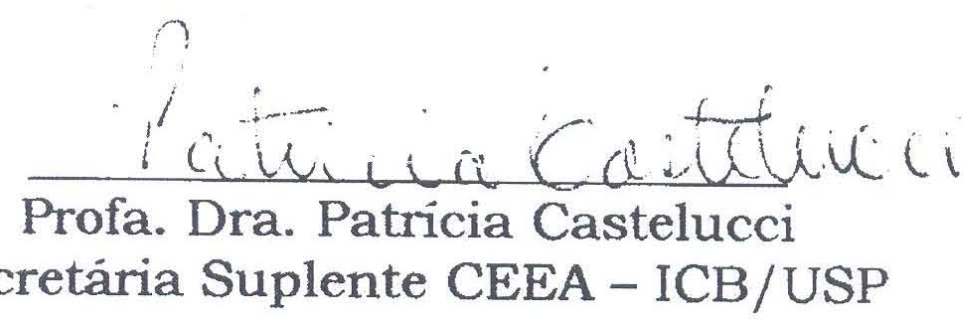


Dedico este Trabalho:

Ao meu pai por ser um exemplo de caráter e força.

A minha mãe por sempre apoiar as minhas escolhas e ser a minha fonte de inspiração em dar aula.

A minha esposa Lucila pela paciência e apoiar nos momentos mais difíceis desse sofrido Doutorado.

Obrigado. 


\section{Agradecimentos}

Ao laboratório de Farmacologia Bioquímica dos Radicais Livres. Laboratório em que participei da formação e onde fui formado como pesquisador.

À FAPESP, agência financiadora do projeto e da minha bolsa (Projeto: 2006/57068-2).

A empresa ITF chemical Ltda por ter doado o sal puro de rosiglitazona para a realização deste trabalho.

A todas as pessoas que tive contato e que participaram direta e indiretamente para a realização deste trabalho. 


\section{Resumo}

Martins-Porto R. Papel dos receptores nucleares ativados por proliferadores de peroxissomos (PPAR) na periodontite induzida em ratos. 2012. [Tese (Doutorado em Farmacologia)] - Instituto de Ciências Biomédicas, Universidade de São Paulo, São Paulo; 2012.

A periodontite está relacionada à presença de associações de bactérias (e seus produtos) e à própria destruição tecidual causada pelas células de defesa do hospedeiro. A produção de citocinas e metabólitos do ácido araquidônico desempenham um importante papel no processo de perda óssea através do aumento no número de osteoclastos. Drogas como o antidiabético rosiglitazona tem sido demonstrado como um inibidor tanto a produção de alguns mediadores inflamatórios (tais como o NO, TNF- $\alpha$ e IL-1) como a osteogênese, a qual ocorre pela ativação do receptor nuclear PPAR- $\gamma$. O objetivo deste trabalho foi estudar a participação dos receptores PPAR- $\gamma$ na perda óssea secundária à periodontite induzida, através da avaliação dos efeitos do tratamento de 21 dias dos animais com o maleato de Rosiglitazona (Avandia) administrado por gavagem (CMC como veículo) e com o sal puro do maleato de rosiglitazona administrado por via intraperitoneal (DMSO como veículo). Investigar possíveis alterações na expressão gênica ds receptores PPARs ( $\alpha, \beta$ e $\gamma$ ) das isoformas das óxido nítrico sintases (e, n e iNOS) e dos receptores Osterix, RUNX2, TRAF2, TRAF6, RANKL no osso alveolar desses mesmos animais. 0 tratamento crônico de 21 dias com sal puro do maleato de rosiglitazona (i.p) e Avandia (v.o) aumentou a distância da JEC/COA quando comparado aos grupos que receberam os respectivos veículos. $O$ tratamento com o sal puro de rosiglitazona aumentou a expressão gênica de RANKL, nNOS, iNOS e PPAR- $\gamma$ e diminuiu a expressão gênica de Osterix. $O$ tratamento com 0 Avandia aumentou a expressão gênica de iNOS e PPAR- $\beta$, diminuiu a expressão gênica de TRAF2. Uma hora após a administração de rosiglitazona, observamos maior concentração plasmática por via oral do que por via intraperitoneal. Não foram observadas diferenças significativas nos demais tempos estudados. Três dias de pré-tratamento com DMSO foi capaz de causar diminuição da atividade da NOS independente de cálcio após 16 horas da indução da septsemia. Em conclusão, podemos sugerir que o tratamento com rosiglitazona, independente da via de administração, agravou a perda óssea secundária à periodontite, analisada sete dias após a indução da doença. Esse agravamento é provavelmente devido ao aumento da expressão iNOS, RANKL e TRAF6 (relacionados a atividade de osteoclastos), e diminuição da expressão de Osterix (atividade de osteoblastos). As discrepâncias com os resultados publicados por outros autores podem ser devidas à interferência do DMSO na composição do tratamento, o qual foi evidenciado neste estudo pelos diferentes mecanismos de sinalização observados para cada uma das vias de administração que utilizamos.

Palavras Chave: Periodontite. Inflamação. PPAR. Metabolismo Ósseo 


\begin{abstract}
Martins-Porto R. Role of peroxisome proliferator activated nuclear receptor (PPAR) in induced periodontitis in rats. 2012. [Ph. D. thesis (Pharmacology)] - Instituto de Ciências Biomédicas, Universidade de São Paulo, São Paulo; 2012.

Periodontitis is associated with bacteria presence (and their products) and tissue destruction caused by the host defense cells. The cytokines and arachidonic acid metabolites production play an important role in bone loss by increasing the osteoclast number. Drugs such as the antidiabetic rosiglitazone has been shown to work as an inhibitor for both the production of several inflammatory mediators (such as NO, TNF- $\alpha$ and IL-1 $\beta$ ) and for osteogenesis, which occurs through PPAR- $\gamma$ nuclear receptor activation. This study aimed to investigate the PPAR- $\gamma$ receptor involvement on bone loss secondary to periodontitis induction, by evaluating the 21 days effects of treatment on animals with Rosiglitazone meleate (Avandia) administered by garage (vehicle $\mathrm{CMC}$ ) and with the pure salt of rosiglitazone maleate administered intraperitoneally (vehicle DMSO). In addition, we investigated possible alterations in PPARs $(\alpha, \beta$ and $\gamma$ ) receptors, nitric oxide synthases isoforms (e, $\mathrm{n}$ and iNOS) and Osterix, RUNX2, TRAF2, TRAF6, RANKL gene expression in alveolar bone on the same animals. Twenty-one days chronic treatment with pure salt of rosiglitazone maleate (i.p) and e Avandia (v.o) increased the JEC/COA distance when compared to their respective vehicles groups. The pure salt of rosiglitazobe maleate treatment increased RANKL, nNOS, iNOS and PPAR- $\gamma$ gene expression and decreased Osterix gene expression. Avandia treatment increased iNOS e PPAR- $\beta$ gene expression and decreased the TRAF2 gene expression. One hour after rosiglitazone administration, we observed a higher plasma concentration when it was orally administered than when it was intraperitoneally administered. No significant differences were observed in other study periods. Three pretreatment days with DMSO were able to cause a calcium independent NOS decreased activity after 16 hours of septsemia induction. In conclusion, we suggest that rosiglitazone treatment, regardless of the administration route, exacerbated secondary bone loss to periodontitis assessed seven days after disease induction. This increase is probably due to iNOS, RANKL and TRAF6 increased gene expression (related osteoblast activity), and Osterix decreased gene expression (osteoblast activity). Discrepancies with published results by others authors may be due DMSO interference in the treatment composition, which was demonstrated in this study by different signaling pathways observed for each administration route used.
\end{abstract}

Keywords: Periodontitis. Inflammation. PPAR. Bone metabolism. 


\section{Lista de Figuras}

Figura 1 - Representação da organização da anatomia periodontal ................................................ 17

Figura 2 - Esquema representativo do metabolismo ósseo em condições fisiológicas. .....

Figura 3 - Esquema representativo da estrutura do domínio do receptores PPARs. Os domínios de ligação ao DNA e ao Ligante são indicados. Os números representam os percentuais de aminoácidos idêntico......

Figura 4 - PPAR-g bloqueia a resposta inflamatória interferindo negativamente com diversas vias de sinalização como aquelas envolvendo NFKB, AP-1 e JACK-STAT.

Figura 5 - Película radiográfica e os pontos de análise utilizados para mensurar a perda óssea decorrente da periodontite.

Figura 6 - Valores da distância da JCE à crista óssea alveolar (em mm), 7 dias após a indução da periodontite, em animais Sham e com peridontite (PERIO), animais com periodontite tratados com CMC (veículo do Avandia), Avandia, DMSO (veículo do sal puro de rosiglitazona) e sal puro de rosiglitazona (ROSIG).

Figura 7 - Valores da distancia da JCE a crista óssea alveolar (em mm), 7 dias após a indução da periodontite em animais com periodontite tratados com CMC e Lipanon.

Figura 8 - Curva farmacocinética da rosiglitazona em ratos 24 horas após a administração de dose única e da vigésima primeira dose (10 mg/kg) de Avandia (V.O) ou maleato de rosiglitazona puro (I.P).

Figura 9 - Avaliação da atividade da NOS presente em homogenates de pulmão de ratos 16 horas após a injeção de LPS. Painéis A mostra a atividade da NOS dependente de cálcio e painéis $B$ mostram a atividade da NOS independente de Cálcio.

Figura 10 - Concentrações séricas de cálcio (painel A), atividades plasmáticas de fosfatase alcalina (painel B) e fosfatase ácida tartarato resistente (TRAP) [painel C] medidas nos grupos de ratos Sham (SH) ou com periodontite tratados com CMC (veículo do Avandia), DMSO (veículo do sal puro de rosiglitazona), Avandia e sal puro de rosiglitazona (Rosig Puro) 7 dias após a indução da doença...... 47 


\section{Lista de Tabelas}

Tabela 1 - Expressão gênica por qPCR para as isoformas de NOS e PPAR em amostras de osso alveolar, 7 dias após a indução da periodontite em animais do grupo Sham e periodontite, periodontite tratado com CMC (veículo do Avandia) e Avandia, DMSO (veículo do sal puro de rosiglitazona) e sal puro de rosiglitazona.

Tabela 2 - Expressão gênica por qPCR para RANKL, TRAF6, TRAF2, RUNX2 and OSTERIX em amostras de osso alveolar, 7 dias após a indução da periodontite, em animais do grupo Sham e periodontite, periodontite tratado com CMC (veículo do Avandia) e Avandia, DMSO (veículo do sal puro de rosiglitazona )e sal puro de rosiglitazona.

Tabela 3 - Parâmetros bioquímicos médios em plasma ou soro de ratos Sham, com periodontite e com periodontite tratados com CMC (veículo do Avandia), Avandia, DMSO (veículo do sal puro de rosiglitazona) e sal puro de rosiglitazona 7 dias após a indução da doença. 


\section{LISTA DE ABREVIATURAS E SIGLAS}

ANVISA - Agencia Nacional de Vigilância Sanitária

AP-1 - Proteína ativadora 1

AST - Aspartato amina transaminase

$\mathrm{BH}_{4}$ - Tetraidrobiopterina

BHT - Butilhidroxitolueno

$\mathrm{Ca}^{2+}-$ Cálcio

CEEA - Comissão de Ética em Experimentação AnimalCMC

$\mathrm{CMC}$ - carboximetilcelulose

COA - Crista óssea alveolar

DMSO - Dimetilsufóxiodo

eNOS - Óxido nítrico sintase endotelial

FAD - Flavina-adenina dinucleotídeo

$\gamma$-GT - Gama glutamil transferase

$\mathrm{H}_{2} \mathrm{O}_{2}$ - Peróxido de hidrogênio

ICB - Instituto de Ciências Biomédicas

IFN $\alpha$ - Interferon-alfa

IFN $\gamma$ - Interferon-gama

iNOS - Óxido nítrico sintase induzida

IL-1 - Interleucina-1

IL-1 $\beta$ - Interleucina-1-beta

IL-1R - Receptor de Interleucina-1

IL2 - Interleucina-2

IL6 - Interleucina-6

i.p. - Intraperitoneal

JEC - Junção esmalte-cemento

L-arg - L-arginina

L-cit - L-citrulina

L-NAME - $\mathrm{N}_{\mathrm{w}}$-nitro L-arginina metilester 
LOD - Limite de detecção

LOQ - limite de quantificação

LLOQ - Limite inferior de quantificação

LPS - Lipopolissacarídeo

MRM - Monitoramento de reação múltipla

NADPH - Fosfato de nicotinamida-adenina dinucleotídeo

nNOS - Óxido nítrico sintase neuronal

NF-kB - Fator nuclear kappa B

NO - Óxido nítrico

NOS - Óxido nítrico sintase

NOH-L-ARG - L-NG-hidroxi-arginina

$\mathrm{O}_{2}-$ - Ânion superóxido

$\mathrm{OH} \cdot$ - Radical hidroxila

ONOO- - Íon peroxinitrito

OPG - Osteoprotegerina

Perio - Periodontite

PG- Prostaglandina

PMN - Polimorfonuclear

PPAR - Receptores nucleares ativados por proliferadores de peroxissomos

PPAR- $\alpha-$ Receptores nucleares ativados por proliferadores de peroxissomos $\alpha$

PPAR- $ß$ - Receptores nucleares ativados por proliferadores de peroxissomos $\beta$

PPAR-g - Receptores nucleares ativados por proliferadores de peroxissomos $\mathrm{g}$

QC - controle de qualidade

15d-PGJ2 - 15-deoxy- $\Delta^{12,14}-P^{-P J}$

RANK - Receptor ativador do fator nuclear kappa B

RANKL- Ligante do receptor ativador do fator nuclear kappa B

RUNX2

$\mathrm{RXR}$ - receptor retinóide $X$

$\mathrm{SH}$ - Sham

TNF- $\alpha$ - Fator de necrose tumoral-alfa

TRAF - Fatores associados ao receptor de TNF

TRAF2 - Fatores associados ao receptor de TNF 2 
TRAF6 - Fatores associados ao receptor de TNF 6

TRAP- Fosfatase alcalina resistente a tartarato

TZD - Tiazolidinodionas

U.A - Unidades arbitrárias

USP - Universidade de São Paulo 


\section{Sumário}

1 INTRODUÇÃO 17

1.1 Características do periodonto humano sadio 17

1.2 Aspectos gerais da doença periodontal 18

1.3 Metabolismo ósseo 19

1.4 Periodontite e doenças sistêmicas 21

1.5 Receptores nucleares ativados por proliferadores de peroxissomos (PPAR - "peroxisome proliferator-activated receptors") 22

2 OBJETIVOS 27

3 MATERIAL E MÉTODOS 28

3.1 Animais e tratamento 28

3.2 Indução de doença periodontal em ratos. 28

3.3 Mensuração da perda óssea $\quad 29$

3.4 Tratamento com Fenofibrato 30

3.5 Reação em cadeia da polimerase - transcriptase reversa em tempo real (qPCR) 30

3.5.1 Extração do RNA total 30

3.5.2 Transcrição do cDNA 31

3.5.3 Reação em cadeia da polimerase (qPCR) quantitativa em tempo real: 31

3.6 Indução da iNOS pelo LPS 32

3.7 Avaliação da atividade de NOS $\quad 32$

3.8 Estudo Farmacocinético da Rosiglitazona 33

3.8.1 Tratamento 33

3.8.2 Extração de Rosiglitazona do Plasma de Ratos 34

3.8.3 Validação Pré-Estudo 34

3.8.4 Descrição Geral das Condições Cromatográficas 35

3.8.5 Parâmetros de deteç̧ão 35

3.8.6 Validação do método analítico 35

3.9 Análises bioquímicas de marcadores da função renal e hepática 36

3.10 Análises bioquímicas de marcadores da atividade óssea 36

3.11 Análise estatística 36

$\begin{array}{ll}4 \text { RESULTADOS } & 37\end{array}$

4.1 Análise da perda óssea alveolar 37

4.2 Reação em cadeia da polimerase - transcriptase reversa em tempo real (qPCR) 37

4.3 Farmacocinético da Rosiglitazona 38

4.4 Atividade da NOS 39

4.5 Análise bioquímica de marcadores da atividade óssea 39

4.6 Análise bioquímica de marcadores da atividade renal e hepática 40

5 DISCUSSÃO 
6 CONCLUSÃO

REFERÊNCIAS 


\section{INTRODUÇÃO}

A doença periodontal representa uma das principais ameaças à saúde bucal, sendo a doença crônica mais prevalente na dentição humana (Taanu, 1997). Tradicionalmente é dividida em duas categorias principais: doenças gengivais (gengivites) e as doenças que envolvem as estruturas de suporte do dente, como as periodontites (Carranza e Newman, 2004). Estudo epidemiológico realizado na zona urbana no Brasil em 1986 demonstrou que $72 \%$ das pessoas apresentavam sinais iniciais ou reversíveis de periodontopatias no grupo com idade entre 35 e 70 anos, dessas, 21,5\% apresentavam periodontite no estágio inicial e $6,5 \%$ periodontite avançada (Pinto e col, 1999). Atualmente a prevalência dessas doenças é desconhecida no Brasil.

O agente etiológico das doenças periodontais é a placa bacteriana, a qual é formada por um conjunto de bactérias, células epiteliais descamadas, leucócitos polimorfonucleares, micoplasmas, leveduras e protozoários (Lindle, 2005).

A progressão das doenças periodontais apresenta-se de forma muito variada, podendo ter períodos de atividade intensa, seguidos por intervalos de estagnação ou remissão, sendo esta evolução influenciada pelas células do sistema imunológico e pelos tipos de agressores microbianos envolvidos (Genco et al., 1997; Carranza e Newman, 2004).

\subsection{Características do periodonto humano sadio}

O periodonto, ou "aparelho de inserção" é o conjunto formado pela gengiva, cemento, osso alveolar e o ligamento periodontal, e cuja função principal é inserir o dente no tecido ósseo dos maxilares e manter a integridade da superfície da mucosa mastigatória da cavidade bucal (Figura 1).

Figura 1 - Representação da organização da anatomia periodontal

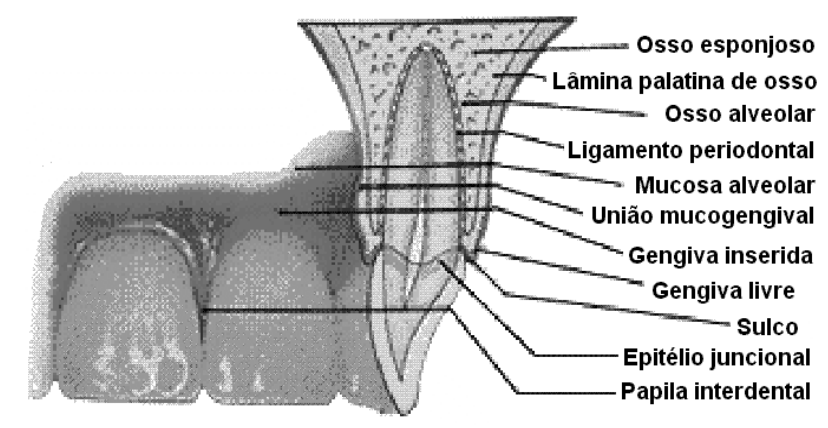

Fonte: http://www.eduardorubio.odo.br 


\subsection{Aspectos gerais da doença periodontal}

Como já mencionado, a doença periodontal compreende um grupo de condições inflamatórias dos tecidos de suporte dos dentes causadas por bactérias. É sugerido que pelo menos dois fatores determinem a resposta inflamatória que gera a perda de inserção: 1.- a presença de bactérias e seus produtos; 2.- a própria destruição tecidual causada pelas células de defesa (Opperman et al , 2001).

Podemos relacionar como fatores de risco das doenças periodontais a má higienização oral (fator etiológico determinante das periodontopatias), os maus hábitos, tais como o fumo e a escovação traumática (fatores modificadores locais), o estresse, a desnutrição e a presença de doenças sistêmicas com, por exemplo, o diabetes mellitus (fatores modificadores sistêmicos) [Opperman et al , 2001].

Temos também os fatores populacionais que afetam a prevalência e a gravidade da doença periodontal, como a idade (quanto maior a idade, maior a prevalência da doença periodontal), o sexo (em geral, os homens possuem maior prevalência e gravidade da doença), a raça (os negros têm maior prevalência quando comparado com os brancos), educação e renda (a doença periodontal é inversamente proporcional ao grau de escolaridade e renda).

A doença periodontal começa com a instalação da placa dental que é um biofilme associado ao hospedeiro, ao redor do dente e tecido gengival. Esse biofilme é formado por diferentes espécies bacterianas que interagem física e fisiologicamente entre si e com o dente.

É difícil responsabilizar patógenos específicos para a destruição do periodonto, visto existirem mais de 300 espécies encontradas na placa bacteriana (Dubreful e Bascones, 1995), o qual demonstra que as patologias periodontais observadas são resultado de uma complexa associação bacteriana (Socransky e Haffajee, 1992) O tecido periodontal doente é reflexo de mudança na microflora da placa que passa de $10^{2}-10^{3}$ bactérias em estado saudável, para $10^{4}-10^{6}$ na gengivite e $10^{5}-10^{8}$ na periodontite (Tanner, 1996).

No curso das periodontites, as taxas elevadas de certas espécies fazem que elas sejam consideradas como patógenos potenciais (Loesche, 1993). Muitas pesquisas sobre fatores de virulência enfocam as propriedades das bactérias relacionadas com a destruição dos tecidos do hospedeiro. Essas propriedades bacterianas podem ser amplamente classificadas como resultantes diretamente na degradação dos tecidos do hospedeiro e como causadoras da liberação de substâncias biologicamente ativas das células do mesmo. 
O sistema imunológico do hospedeiro envolve uma rede complexa de interações entre células e moléculas reguladoras. Uma interação bem caracterizada envolve a liberação de mediadores inflamatórios tais como a interleucina-1 (IL-1), óxido nítrico (NO), fator de necrose tumoral (TNF-a), e prostaglandinas de macrófagos e monócitos expostos a endotoxinas bacterianas (por exemplo, lipopolissacarídeos), e são esses mediadores derivados do hospedeiro os que têm o potencial de estimular a reabsorção óssea e ativar ou inibir outras células do sistema imunológico do organismo responsáveis por destruir tecidos e gerar a perda de função de estruturas anatômicas (Carranza e Newman, 2004).

A exarcerbação da ativação do sistema imunológico é de crucial importância na determinação da severidade e duração da doença, podendo gerar uma destruição tecidual tamanha que pode acarretar na perda do elemento dental (Lundy et al., 2004).

\subsection{Metabolismo ósseo}

O osso é um tecido dinâmico que está em constante remodelação pela ação dos osteoblastos, osteócitos e osteoclastos. Osteoclastos são células multinucleares que degradam matriz óssea mineralizada, derivadas da diferenciação terminal de células progenitoras hematopoiéticas que originam a linhagem monócitos / macrófagos (Haynes, 2004). Os osteoblastos, por sua vez, são as células responsáveis pela secreção da matriz orgânica óssea que posteriormente se calcifica e forma 0 osso (Stevens e Lowe, 2001). Com o desenvolvimento ósseo, alguns osteoblastos são aprisionados no interior da matriz óssea e passam a ser chamados de osteócitos.

Em condições normais, os osteoblastos regulam a diferenciação e função dos osteoclastos (Martin et al., 1994). No caso de processos inflamatórios crônicos (como na periodontita), uma grande variedade de células (tais como da linhagem monócito / macrófago e macrófagos maduros) também estimulam a diferenciação dessas células (Martin et al., 1994; Takahashi et al., 1998; Quinn et al., 1998).

O fator chave na estimulação da formação de osteoclasto em condições fisiológicas é a ligação do RANK (receptor ativador do fator nuclear kappa B) com o seu ligante RANKL (ou fator de diferenciação de ostesteoclastos), sendo que o RANKL é expresso na superfície celular de osteoblastos, e o seu receptor, o RANK, está presente nas células precursoras de osteoclastos (Yasuda et al., 1998; Lacey et al., 1998) [vide figura 02]. 
A osteoprotegerina (OPG; molécula solúvel tipo-receptor de TNF) é um inibidor natural da interação RANKL-RANK (mediada pela sua ligação ao RANKL) e é produzida tanto fisiologicamente quanto em processos inflamatórios [vide figura 02]. Pesquisas utilizando anticorpos dirigidos contra a OPG tem sido realizadas para estudar esta via em uma variedade de tecidos saudáveis e inflamados. Os trabalhos de Crotti et al. (2002) e Haynes et al. (2003) tem demonstrado que em humanos, a proteína RANKL é predominante em células inflamatórias (leucócitos ativados que migraram para o foco inflamatório) e tecidos adjacentes à regiões de perda óssea patológica na artrite reumatóide. Os osteoblastos perdem a capacidade de controlar a diferenciação dos osteoclastos que passam a ser estimulados principalmente pelos leucócitos ativados

Linfócitos CD3+ formam os tipos de células predominantes que expressam a proteína RANKL na doença periodontal e na artrite reumatóide em humanos (Crotti et al., 2002). Esse ligante do receptor RANK também é expresso em monócitos, macrófagos, células multinucleares que expressam CD68 e em células endoteliais (Haynes, 2004).

Citocinas pró-inflamatórias tais como TNF- $\alpha$ e metabólitos do ácido araquidônico (como os leucotrienos) presentes em grandes quantidades na artrite reumatóide, periodontite e tecidos periprotéticos, aumentam a formação de osteoclastos (Xu et al., 1996). Tem-se demonstrado que o TNF- $\alpha$ estimula a osteoclastogênese in vitro através da interação direta com o RANK na ausência de RANKL ou através da ativação dos próprios receptores para TNF $\alpha$ (TNFR1 e TNFR2) [Udagawa, 2003]. 0 receptor de Interleucina 1 beta (IL-1 $\beta$ ), quando ativado, também pode estimular a ativação de osteoclastos. O bloqueio da atividade de TNF $\alpha$ através de antagonistas ou anticorpos, não somente reduz a resposta inflamatória como também pode inibir a reabsorção óssea através da redução da atividade do RANKL presente no tecido. A supressão da formação de osteoclastos tem sido observada em modelos animais de artrite reumatóide através de várias combinações de inibição de TNF- $\alpha$, IL-1 $\beta$ ou RANKL. (Zwerina et. al., 2004).

No processo de diferenciação e ativação de osteoblasto e osteoclastos, após a interação dos agonistas com os receptores presentes na membrana plasmática, são ativados fatores transcricionais predominantes nessas células. RUNX2 também conhecido como CBFA1 é membro da família de fatores transcricionais de domínio RUNT (Shembade et al.,2010) e está envolvido nas duas fases na diferenciação: A primeira que consiste na diferenciação das células mesenquimais multipotenciais em pré-osteoblastos e a segunda que é a diferenciação dos pré-osteoblastos em osteoblastos funcionais (Ducy et al., 2009; Karsenty, 2008; Nakashisma et al., 2002). Já o Osterix é uma proteína com domínio dedo de zinco com traços do fator transcricional específico de osteoblasto (Nakashisma et al., 2002). 
Esse é ativado na segunda fase da diferenciação dos osteoblastos e age provavelmente suprimindo fatores transcricionais que direcionariam essas células a se diferenciarem em condrócitos, além de estár envolvido na ativação do RUNX2 (Karsenty 2008). Em relação ao osteoclastos, após a ativação de receptores como RANK, receptores de TNF- $\alpha$ (TNFR1 e TNFR2) e o receptor de Interleucina 1 (IL$1 R$ ) são recrutados segundos mensageiros da família de fatores associados ao receptor de TNF (TRAF), principalmente TRAF2 e TRAF6, que são fundamentais para a diferenciação e ativação dos osteoclastos (Udagawa, 2003).

Figura 2 - Esquema representativo do metabolismo ósseo em condições fisiológicas.

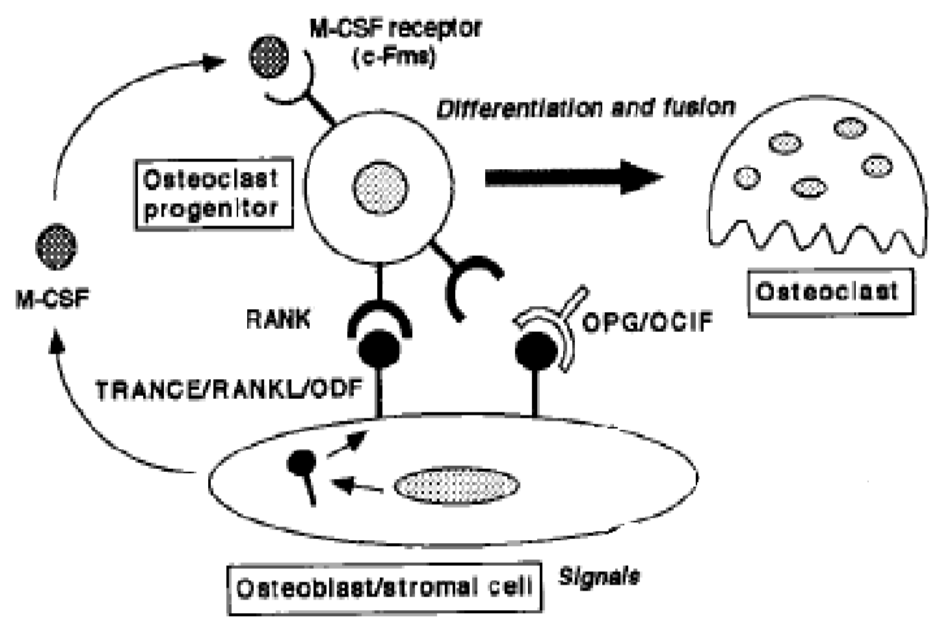

Fonte: Yasuda (1997)

\subsection{Periodontite e doenças sistêmicas}

Recentes estudos têm demonstrado que as doenças periodontais são fatores de risco para doenças sistêmicas como acidentes vasculares cerebrais, infarto agudo do miocárdio, mortes prematuras de bebês gerados por mães com doença periodontal avançada, problemas renais e Diabetes mellitus (Loesche, 1993; Mattila et al., 1995; Genco, 1996; Joshipura et al., 1996; Herzberg e Meyer, 1998; Mealey, 2008; Vettore, 2008; Buhlin, 2009, de Pablo, 2009).

O mecanismo se dá pela queda na corrente sanguínea de produtos bacterianos (como LPS) e de mediadores inflamatórios como: prostaglandina E2, TNF $\alpha$, Interleucina-1 e Interleucina-6 que são produzidos em grandes quantidades na periodontite. Esses produtos alcançam partes distantes do 
organismo provocando uma série de alterações no seu funcionamento. Um exemplo desse mecanismo se dá pela interação bidirecional da periodontite com o diabetes mellitus.

Medicamentos utilizados para o tratamento e/ou controle das doenças sistêmicas também podem agir controlando a inflamação periodontal por terem, na maioria das vezes, como resultado de suas ações, a diminuiçao dos mesmos mediadores inflamatórios envolvidos na periodontite (prostaglandina E2, TNF $\alpha$, Interleucina-1, Óxido nítrico e Interleucina-6). Podemos tomar como exemplo os dois principais medicamentos utilizados no tratamento do Diabetes Mellitus do tipo 2 (resistência a insulina): a metformina que vem sendo mostrado como inibidor da produção de óxido nítrico em culturas de macrófagos ativados por LPS (Kato et al., 2010) e a classe de drogas tiazolidinodionas (principalmente rosiglitazona, pioglitazona) que agem através da ativação do receptor nuclear PPARs (receptor nuclear ativado por proliferadores de peroxissomos), principalmente a isoforma gama que desencadeiam uma série de efeitos anti-inflamatório (Wang e Dubois 2010; Lee et al., 2010).

1.5 Receptores nucleares ativados por proliferadores de peroxissomos (PPAR - "peroxisome proliferator-activated receptors")

Os PPARs são receptores nucleares membros da superfamília dos receptores intracelulares hormonais que medeiam a transcrição gênica de fatores após serem ativados. Essa superfamília incluem os receptores para esteróides, hormônio tireoideano, vitamina D e ácido retinóico (Mangelsdrof et al., 1995).

O PPAR precisa forma heterodímero com o receptor retinóide $X(R X R)$ para ligar-se ao elemento responsivo do proliferador de peroxisomo (PPRE, de sequência consenso repetida TGACCTnTGACCT). RXR também forma heterodímeros com outros membros da superfamília dos receptores nucleares, e essas interações influenciam a ativação transcricional regulada pelos PPAR (Tan et al., 2004).

Até o momento, três isotipos de PPAR foram identificados: PPAR- $\alpha$ (ou NR1C1, membro 1 do grupo $C$ da sub-família 1 dos receptores nucleares), PPAR-ß (NR1C2 ou PPAR- $\delta$ ) e PPAR- $\gamma$ subdividido em PPAR- $\gamma 1$ e PPAR- $\gamma 2$ (NR1C3). O primeiro clonado foi o PPAR- $\alpha$ em 1990 por Issemann and Green que demonstraram que esse receptor órfão quando estimulado por fenofibrato ou outros conhecidos proliferadores de peroxissomos provocava a proliferação dessa organela. A proliferação de perixissomo, desencadeada pela ativação do PPAR- $\alpha$, é observada somente em 
roedores e não em humanos (kliewer et al.,2001 ).Em 1992 esse receptor foi clonado em Xenopus laevis juntamente com outros dois receptores com estruturas semelhantes chamados de PPAR-ß e PPAR- $\gamma$ (Dreyer et al., 1992). Os nomes PPAR-ß e PPAR- $\gamma$ não são adequados para os receptores uma vez que esses novos subtipos de PPAR não foram associados à proliferação de peroxissomo (Kliewer et al., 2001).

Como todos os receptores nucleares, os receptores PPARs possuem uma estrutura modular composta de um domínio aminoácido-terminal (NTD), um central e bem conservado domínio de ligação ao DNA (DLD) e um moderado e conservado domínio carboxiterminal, melhor conhecido como domínio de ligação ao ligante. A Figura 2 mostra um esquema da estrutura molecular dos PPARs com seus respectivos percentuais de aminoácidos idênticos.

Figura 3 - Esquema representativo da estrutura do domínio do receptores PPARs. Os domínios de ligação ao DNA e ao Ligante são indicados. Os números representam os percentuais de aminoácidos idêntico

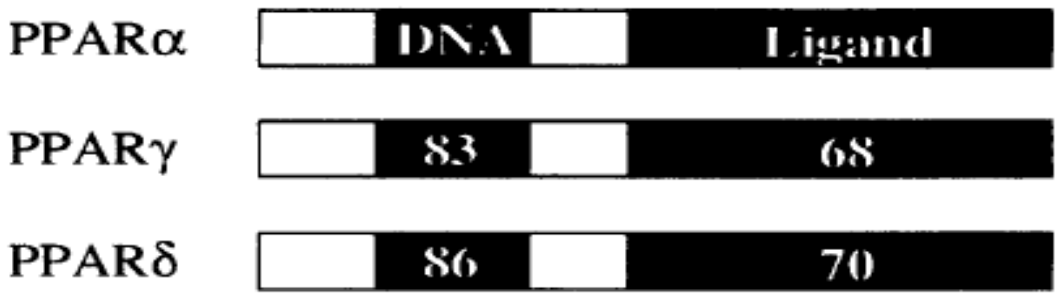

Fonte: Millard (2001)

O PPAR- $\alpha$ é expresso em tecidos com alto catabolismo de ácidos graxos (tais como rim, músculo cardíaco e fígado; Berger e Moller, 2002). No fígado, a sua ativação estimula a oxidação de ácidos graxos, cetogênese e regula a produção de apolipoproteínas (Tan et al., 2004); drogas hipolipidemiantes, como os fibratos fenofibrato ou genfibrozil, agem através da ativação deste receptor (Rosen et al., 2000).

PPAR-ß é encontrado em grandes quantidades em cérebro de embrião de rato e pode ter um papel crítico na regulação da diferenciação celular no sistema nervoso central (Saluja et al., 2001; Berger e Moller, 2002). Também tem sido implicado em outros processos biológicos, tais como transporte de colesterol (Oliver et al., 2001), formação de tumores no cólon (He et al., 1999), desenvolvimento da placenta (Tan et al., 2005) e recentemente à aterosclerose (Lee et al.,2003). 
Os receptores PPAR- $\gamma 1$ e PPAR- $\gamma 2$ estão envolvidos em numerosas manifestações clínicas como obesidade, arteriosclerose e diabetes (Kersten et al., 2000). O PPAR- $\gamma 2$ é expresso em altos níveis no tecido adiposo, já o PPAR- $\gamma 1$ possui uma maior distribuição no organismo, sendo bem expresso em macrófagos, osteoblastos, células $T$, células endoteliais, células do músculo liso vascular, células tumorais em cultura, assim como em células epiteliais de cólon, mama, ovário e próstata (Diab et al., 2002; Han et al., 2004; Rosen et al., 2000).

O PPAR- $\gamma$ é um ligante para as tiazolidinodionas (TZDs). Diversas TZDs como a troglitazona, pioglitazona, rosiglitazona e a ciglitazona foram desenvolvidos para o tratamento do diabetes tipo 2. Essas drogas aumentam a sensibilidade à insulina através da ativação do receptor PPAR- $\gamma$ em adipócitos periféricos e promovendo a sua diferenciação. Como resultado, ocorre queda na concentração plasmática de ácidos graxos, e redistribuição de lipídios e metabólitos de ácidos graxos intracelulares de órgãos responsivos à insulina (tais como fígado e músculo) para dentro dos adipócitos periféricos (Mayerson et al., 2002; Berger e Moller, 2002). É possível que o aumento da sensibilidade à insulina provocada pela rosiglitazona no diabetes tipo 2 possa ser provocado por alteração da concentração de TNF- $\alpha$ ou de hormônios derivados de adipócitos, tais como a adiponectina (Yamauchi et al., 2001) ou resistina (Steppan et al., 2001).

Todos os três isotipos de PPAR estão envolvidos em diferentes aspectos da inflamação. Tem sido demonstrado que ligantes do PPAR- $\gamma$ como as tiazolidinadionas ou a prostaglandina 15-deoxy- 12 , 14 - PGJ2 (15d-PGJ2) endógena inibem a produção de NO, TNF- $\alpha$, IL-1 e IL-6 induzida pelos ésteres de forbol em monócitos e macrófagos (via repressão gênica), e antagonizam a atividade dos fatores transcricionais envolvidos, tais como NFKB, STAT e AP-1, de forma independente de ligação ao DNA (Diab et al, 2002; Ricote et al.,1998; (vide Figura 3).

Os ligantes de PPAR- $\gamma$ são potentes moduladores do crescimento de tumores de próstata, colo-retal, e mama (Elstner et al., 1998; Sarraf et al., 1999), induzindo apoptose de macrófagos, fibroblastos e células endoteliais (Diab et al., 2002), além de efeitos benéficos em processos inflamatórios intestinais (Su et al., 1999), na artrite (Kawahito et al., 2000) e arteriosclerose (Ricite et al., 1998). Porém, no caso do estudo dos tumores, trabalhos recentes mostram que ligantes do PPAR- $\gamma$, como a rosiglitazona e a troglitazona, quando ultlizados em grandes doses, podem agir de maneira independente do receptor ativando enzimas oncomoduladoras da família das MAPK (mitogen-activated protein kinase) e potencializando o crescimento tumoral. A ativação das MAPK fosforila o receptor PPAR- $\gamma$ impedindo a transcrição gênica e promovendo a proliferativa das células tumorais (Burgermeister et al., 2008). 
Figura 4: PPAR- $\gamma$ bloqueia a resposta inflamatória interferindo negativamente com diversas vias de sinalização como aquelas envolvendo NFKB, AP-1 e JACK-STAT.

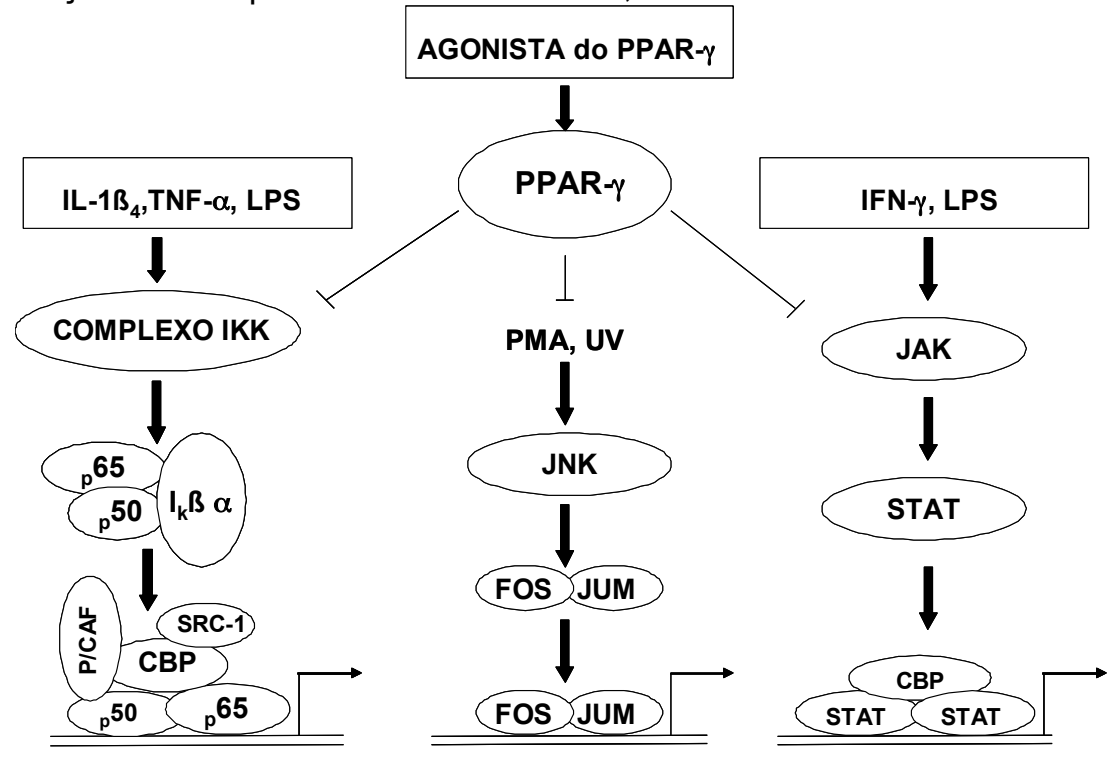

Fonte: Lidstrom (2005)

No caso do tratamento da artrite reumatóide, os agonistas PPAR- $\gamma$ agem através da inibição da angiogênese, e induzindo a apoptose de macrófagos, células sinoviais e endoteliais. Estes eventos resultam em redução da formação do pannus (isto é, o tecido fibroso e de granulação constituído principalmente por macrófagos e fibroblastos) responsável pela destruição da cartilagem e do osso articular (Kawahito et al., 2000).

Como mencionado acima, o PPAR- $\gamma$ tem importante papel regulador da diferenciação de células do tecido adiposo. Os adipócitos são células especializadas em armazenar lipídios (Stevens e Lowe, 2001) e compartilham com os osteoblastos a mesma célula progenitora. Essas células progenitoras são as células tronco mesenquimais multipotenciais da medula óssea, cuja diferenciação em adipócitos ou osteoblastos é definida pelas moleculas PPAR- $\gamma$ ou Runx2, respectivamente (Hiroshi et al., 2004).

Hiroshi et al. (2004), utilizando camundongos com 50\% de redução na expressão de PPAR- $\gamma$ (PPAR- $\gamma+/-$, haplodeficientes) observaram que os animais com genótipo PPAR- $\gamma+/-$ apresentaram maiores densidades óssea do que os animais selvagens independente da idade (entre 8 e 52 semanas de vida). Os animais com genótipo PPAR- $\gamma+/$ - apresentaram maiores níveis de mRNA para moléculas que estimulam a diferenciação em osteoblastos como a Runx2, osterix e Lrp5, o qual parece ocorrer através de estimulação direta da transcrição destes genes, sem 0 envolvimento do elemento responsivo ao PPAR- $\gamma$, cuja seqüência não foi identificada na região do promotor desses genes. Nesse 
mesmo estudo, os autores relatam que a expressão gênica de PPAR- $\gamma$ em pacientes idosos com fratura de fêmur é maior do que aquela observada em jovens, sugerindo que o PPAR- $\gamma$ iniba indiretamente a osteogênese através da estimulação da adipogênse.

Em relação à periodontite existem dois trabalhos na literatura com 0 agonista PPAR- $\gamma$ (rosiglitazona) sobre à perda óssea, no qual, Di Paola et al. (2007) e Hassumi et al (2009) utilizaram em ratos wistar macho uma dose de $10 \mathrm{mg} / \mathrm{kg}$, usando como veículo o Dimetilsufóxiodo (DMSO 10\%), intraperitoneal, durante 8 e 30 dias (sem prétratamento), respectivamente. Observaram uma diminuição tanto da perda óssea decorrente da periodontite como de alguns parâmetros inflamatórios (migração de neutrófilos, expressão da óxido nítrico sintase induzida, formação de proteínas nitradas e extravasamento plasmático). No entanto, testes em nosso laboratório com diferentes doses de maleato de rosiglitazona (droga adquirida em farmácia com o nome comercial de Avandia) administrada por via oral durante 22 dias mostram um aumento de perda óssea sete dias após a indução da periodontite por ligadura. 


\section{OBJETIVOS}

Com base nas informações da literatura expostos até aqui, os objetivos da presente trabalho foram, a saber,

1. Estudar a participação dos receptores PPAR- $\gamma$ na perda óssea secundária à presença de doença periodontal induzida, através da avaliação dos efeitos do tratamento dos animais com 0 maleato de Rosiglitazona (Avandia) administrado por gavagem e com o sal puro do maleato de rosiglitazona administrado por via intraperitoneal;

2. Avaliar a expressão gênica dos receptores PPAR-y em ratos sadios e com doença periodontal induzida bem como as outras isoformas desse receptor (PPAR- $\beta$ e PPAR- $\alpha$ );

3. Investigar possíveis alterações na expressão gênica das isoformas das óxido nítrico sintases (e, n e iNOS), em osso alveolar de ratos com periodontite e sob tratamento com rosiglitazona (droga comercial- Avandia ou o sal puro do maleato de rosiglitazona);

4. Quantificar a expressão gênica de Osterix, RUNX2, TRAF2, TRAF6, RANKL em amostras de osso alveolar de animais com periodontite tratados e não tratados com sal puro de maleato de rosiglitazona ou a droga comercial- Avandia; 


\section{MATERIAL E MÉTODOS}

3.1 Animais e tratamento

Ratos Wistar do sexo masculino pesando 180 - 220 foram tratados com sal puro de rosiglitazona (10 mg/kg/day, i.p) rosiglitazona comercial (Avandia, $10 \mathrm{mg} / \mathrm{kg} / \mathrm{day}$, v.o) ou veículo (0.5\% carboximetilcelulose - CMC, v.o ou dimetilsulfóxido- DMSO, i.p., ambos $1 \mathrm{~mL} / \mathrm{kg}$ ) durante 14 dias prévios a indução da periodontite e até o dia do sacrifício. O DMSO foi utilizado como veículo para o sal puro de rosiglitazona e o CMC foi utilizado com veículo para a rosiglitazona comercial (protocolo aprovado pelo comitê de ética e experimentação animal numero 077, folha 33, livro 2).

\subsection{Indução de doença periodontal em ratos.}

Os animais foram anestesiados com hidrato de cloral sódico (7 mg/kg; i.p.), a periodontite foi induzida com a colocação de um fio de sutura de algodão 4-0 na cervical do primeiro molar inferiores direito, e atado pela face mesial do dente, (Holzhausen et al., 2002). No grupo de animais Sham o fio de sutura foi retirado imediatamente após o procedimento (grupo sham).

Desta forma, os seguintes grupos foram definidos:

Sham;

Periodontite;

Periodontite tratado com CMC (CMC);

Periodontite tratado com DMSO (DMSO);

Periodontite tratado com sal puro de rosiglitazona (Rosig);

Periodontite tratado com Avandia (Avan).

Depois de 7 dias, os grupos de animais foram sacrificados e a mandíbula do lado direito removida para mensuração da perda óssea alveolar (distância em mm da junção cemento-esmalte à crista óssea alveolar na mesial dente com ligadura) através da radiografia digital. 0 osso alveolar foi removido para investigar a expressão gênica de marcadores de ativação e diferenciação de ostoblastos (RUNX2, Osterix) e osteoclastos (TRAF6, TRAF2, RANKL), isoformas de óxido nítrico sintases (e, n e iNOS) e isoformas de PPARs ( $\alpha, \beta e \gamma)$. 


\subsection{Mensuração da perda óssea}

As mandíbulas foram removidas após o sacrifício dos animais. Radiografias digitais padronizadas foram obtidas usando um sistema de imagem computadorizada que utiliza um sensor com um filme de raio-x.

O sensor foi exposto à $65 \mathrm{KV}$ e $10 \mathrm{~mA}$ com o tempo de exposição de 12 impulsos/segundo. $\mathrm{A}$ distância do cone até o filme foi de $40 \mathrm{~cm}$, e uma escala de alumínio foi colocado sobre o sensor para dar uma referência da densidade radiográfica. A distância entre a junção esmalte-cemento (JEC) e a crista óssea alveolar foi determinada na superfície mesial do primeiro molar inferior direito empregando o software AlphaEase FC (Alpha Innotech, EUA) [Holzhausen et al., 2002; Herrera et al., 2011].

A perda óssea de cada mandíbula foi avaliada por 3 examinadores independentes (que desconheciam o grupo ao qual pertencia cada amostra) e a média aritmética dos valores foi então calculada.

Figura 5 - Película radiográfica e os pontos de análise utilizados para mensurar a perda óssea decorrente da periodontite.

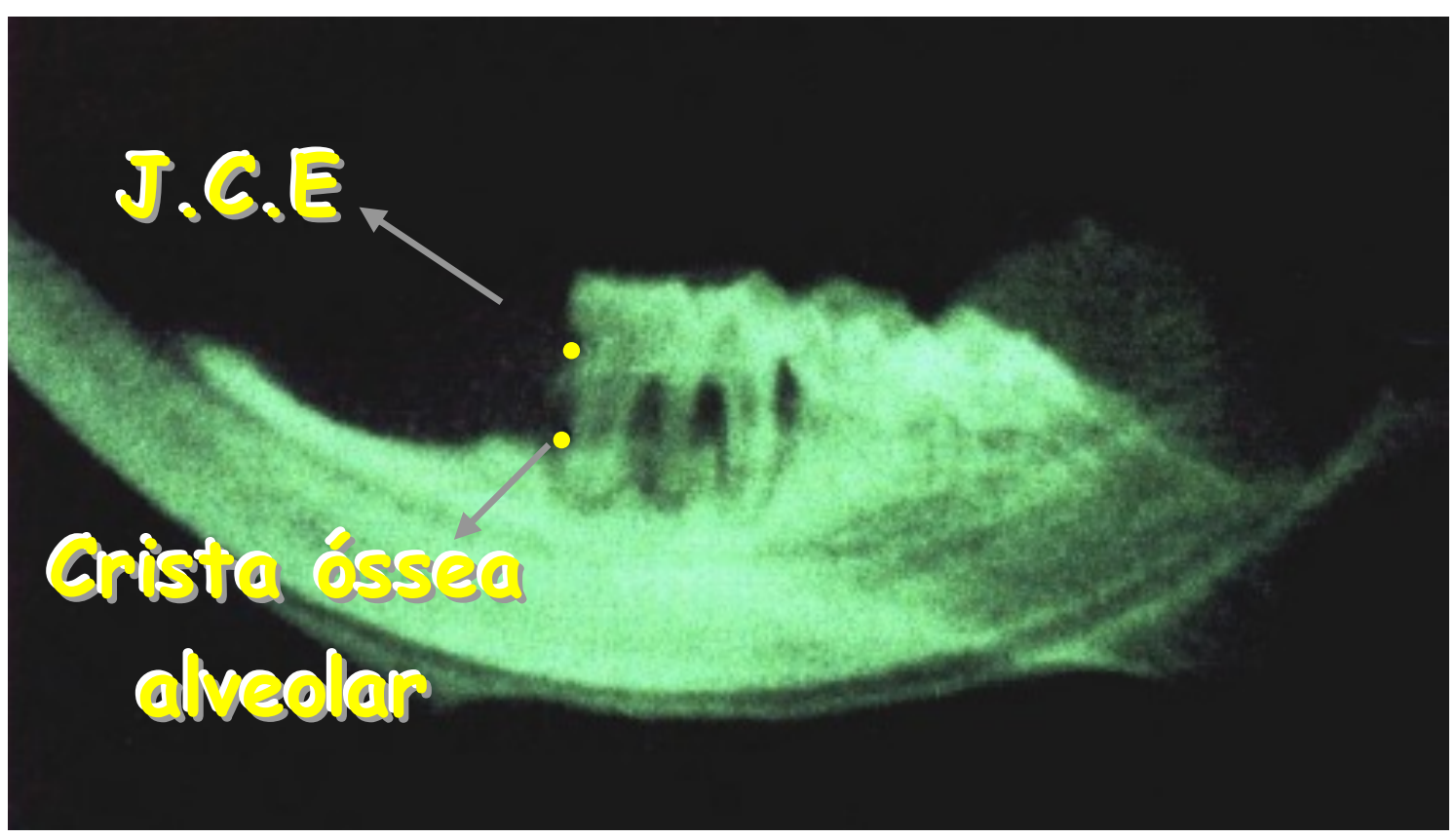

Fonte: Herrera (2010) 
Com o objetivo de verificar a influência da ativação do receptor PPAR- $\alpha$ em nossos resultados, decidimos utilizar o agonista Fenofibrato (Lipanon, FARMASA BR) seguindo o mesmo esquema experimental de indução de periodontite e tratamento com rosiglitazona. Ratos Wistar (180-220g) foram tratados com Lipanon (50 mg/kg/dia, i.p) ou veículo (dimetilsulfóxido - DMSO, i.p., $1 \mathrm{~mL} / \mathrm{kg}$ ) durante 14 dias prévios à indução da periodontite e até o dia do sacrifício. A periodontite foi induzida e após 7 dias, os grupos de animais foram sacrificados e a mandíbula do lado direito removida para avaliação da perda óssea alveolar (em mm) através de radiografia digital

3.5 Reação em cadeia da polimerase - transcriptase reversa em tempo real (qPCR)

A presença de mRNA para os diversos genes estudados (como medida do grau de expressão gênica) foi avaliada pela reação em cadeia da polimerase após transcrição reversa (qPCR) em tempo real. Amostras de tecido ósseo alveolar foram removidas dos animais e imediatamente congeladas em nitrogênio líquido e mantidas a $-70^{\circ} \mathrm{C}$ até o processamento das amostras.

\subsubsection{Extração do RNA total}

O RNA total foi extraído usando o reagente Trizol (Gibco BRL, EUA), conforme o método indicado pelo fabricante, posteriormente dissolvido em água tratada com DEPC e a integridade do RNA isolado foi verificado através de eletroforese em gel de agarose contendo brometo de etídio para revelação das bandas sob luz ultravioleta.

Posteriormente, o RNA foi dissolvido com $50 \mu$ de água tratada com DEPC. Alíquotas desta solução foram diluídas 1:1000, as absorbâncias medidas a $260 \mathrm{~nm}$ e as concentrações de RNA total foram calculadas considerando a relação: $1 \mathrm{AU}=40 \mu \mathrm{g} / \mathrm{ml}$. 
Cuidadosamente, $1 \mu \mathrm{l}$ de oligo dT (GIBCO BRL, EUA) $4 \mu \mathrm{l}$ de tampão de reação (5X first strand buffer), $1 \mu$ l de dNTP (10 mM, Amersham, Inglaterra), $2 \mu$ l de DTT (0,1 M), $1 \mu$ l de inibidor de RNAses (RNAseOUT, Amersham, Inglaterra) $1 \mu \mathrm{l}$ de DNAse 1 e $3 \mu \mathrm{l}$ de RNA foram misturados. A mistura foi aquecida a $37^{\circ} \mathrm{C}$ durante 10 minutos e $75^{\circ} \mathrm{C}$ por 5 minutos, posteriormente adicionou-se $1 \mu \mathrm{da}$ enzima RT (transcriptase reversa - MMLV, GIBCO BRL, EUA) e novamente aquecida a $37^{\circ} \mathrm{C}$ por $1 \mathrm{~h}$. Posteriormente, as amostras foram aquecidas a $75{ }^{\circ} \mathrm{C}$ durante $15 \mathrm{~min}$. e a $37{ }^{\circ} \mathrm{C}$ por $2 \mathrm{~min}$. As amostras foram mantidas a $-20^{\circ} \mathrm{C}$ até serem submetidas ao $\mathrm{PC}$.

3.5.3 Reação em cadeia da polimerase (qPCR) quantitativa em tempo real:

Os primers utilizados (segundo as seqüências mostradas no quadro a seguir que foram posteriormente confirmadas acessando o banco de dados online UCSC genome bioinformatics) foram diluídos a uma concentração de 100 pmoles/ul (solução estoque) com $\mathrm{H}_{2} \mathrm{O}$ Milli-Q autoclavada.

Quadro 1 - Sequência dos primers utilizados para análise do q-PCR

\begin{tabular}{|c|c|c|}
\hline Osterix & $\begin{array}{l}\text { CCACCCATTGCCAGTAATCT } \\
\text { GGACTGGAGCCATAGTGAGC }\end{array}$ & 98 \\
\hline RANKL & $\begin{array}{l}\text { ACAGCGCTTCTCAGGAGTTC } \\
\text { TTGATGGTCAGGTGAGCAAA }\end{array}$ & 102 \\
\hline RUNX2 & $\begin{array}{l}\text { GAGCTACGAATTGCCTCTGC } \\
\text { TGGGGAGGATTTGTCAAGAC }\end{array}$ & 128 \\
\hline TRAF2 & $\begin{array}{l}\text { TGTTCAGCCTGCAGAAACAT } \\
\text { GTGAACACAGGCAGCACAGT }\end{array}$ & 123 \\
\hline TRAF6 & $\begin{array}{l}\text { TGCAAAAGATGGAGCTGAGA } \\
\text { TGTCTCCTGGGACAATCCTC }\end{array}$ & 139 \\
\hline HPRT & $\begin{array}{l}\text { AAGCTTGCTGGTGAAAAG GA } \\
\text { TGATTCAAATCCCTGAAGTC }\end{array}$ & 129 \\
\hline PPAR- $\gamma$ & $\begin{array}{l}\text { CACAATGCCATCAGGTTTGG } \\
\text { CAGCTTCTCCTTCTCGGC CT }\end{array}$ & 133 \\
\hline PPAR- $\beta$ & $\begin{array}{l}\text { GACAGGAGCTAGGGGATTCTG } \\
\text { CGAGTCCCACACGCATAAC }\end{array}$ & 122 \\
\hline PPAR- $\alpha$ & $\begin{array}{l}\text { CTGGTCAAGCTCAGGACACA } \\
\text { CAAGTGGGGAGAGAGGACAG }\end{array}$ & 119 \\
\hline iNOS & $\begin{array}{l}\text { AAAATGGTTTCCCCC AGT TC } \\
\text { GTCGATGGAGTCACATGCAG }\end{array}$ & 82 \\
\hline eNOS & $\begin{array}{l}\text { AGCATGAGGCCTTGGTATTG } \\
\text { CCCGACATTTCCATCAGC }\end{array}$ & 100 \\
\hline nNOS & $\begin{array}{l}\text { CACCTGAAGAGCACACTGGA } \\
\text { GGCTAGAGGAAGAGCTGGT }\end{array}$ & 126 \\
\hline
\end{tabular}

Fonte: Martins-Porto R (2012) 
A reação de qPCR foi realizada em um volume final de $12 \mu$ l contendo $3 \mu$ l de cDNA (amostra), diluído 1:10; $1,5 \mu$ l do primer $1(0,3 \mu \mathrm{M}), 1,5 \mu \mathrm{l}$ do primer $2(0,3 \mu \mathrm{M})$ e $6 \mu \mathrm{l}$ de Syber Green. 0 primer de HPRT1 (hipoxantina guanina fosforibosil transferase) foi utilizado como gene normalizador.

As amostras da reação, em duplicatas, foram adicionadas à placa de 96 poços (MicroAmp, Applied Biosystems, EUA) para amplificação e leitura no equipamento Mx3000P (Stratagene, EUA). 0 equipamento para os ciclos de amplificação a seguir: 10 min a $94{ }^{\circ} \mathrm{C}$ para ativação da enzima, seguido por 40 ciclos de amplificação.

A análise dos dados foi realizada utilizando o software REST 2005 disponível em http://www.gene-quantification.de/download.html. (Pfaffl 2001; 2002).

\subsection{Indução da iNOS pelo LPS}

Com o objetivo de verificar a ação do DMSO sobre a atividade enzimática da iNOS, ratos Wistar machos (180-220g) foram tratados com dimetilsulfóxido DMSO 10\%, i.p.,1 mL/kg durante 3 dias prévios a indução do choque endotoxémico e até o dia do sacrifício. Os grupos controle não receberam tratamento com DMSO. A endotoxemia foi induzida pela injeção de LPS ( $3 \mathrm{mg} / \mathrm{kg}$, i.v.) e dezesseis horas depois da administração de LPS, pulmões e cérebros foram removidos para a determinação da atividade da óxido nítrico sintase.

\subsection{Avaliação da atividade de NOS}

O método utilizado está baseado na conversão da $\left[{ }^{3} \mathrm{H}\right] \mathrm{L}$-arginina para $\left[{ }^{3} \mathrm{H}\right] \mathrm{L}$-citrulina, conforme descrito por Bricola et al., 2003.

As amostras foram pesadas e homogeneizados em 5 volumes de tampão Tris $50 \mathrm{mM}(\mathrm{pH} 7,4)$ que continha $1 \mathrm{mM}$ de L-citrulina, 0,1 mM de EDTA, $1 \mathrm{mM}$ de ditiotreitol (DTT) e $1 \mathrm{mM}$ de PMSF. Os homogenatos foram centrifugados a $10.000 \mathrm{~g}$ por $10 \mathrm{~min}$ e a atividade foi medida no sobrenadante.

Cinquenta microlitros de amostra foram incubadas em um meio que continha $10 \mu \mathrm{l}$ de $\mathrm{CaCl}_{2}(2$ mM), $10 \mu \mathrm{l}$ de uma mistura dos cofatores (NADPH 1 mM, calmodulina -CaM-, $10 \mu \mathrm{g} / \mathrm{ml}$ ) e $10 \mu \mathrm{l}$ de Larginina $10 \mu \mathrm{M}$ contendo $100.000 \mathrm{dpm}$ de [2,3,4,5-3 $\mathrm{H}] \mathrm{L}$-arginina mono hidrocloreto (Amersham Pharmacia, Inglaterra) em temperatura ambiente $\left(25-27^{\circ} \mathrm{C}\right)$, durante 30 minutos. Todos os reagentes foram preparados em tampão Tris $50 \mathrm{mM}(\mathrm{pH} 7,4)$. Após este período, a reação foi interrompida pela 
adição de $1 \mathrm{ml}$ de tampão HEPES 20 mM, pH 5.4 contendo 1mM de EGTA e $1 \mathrm{mM}$ de EDTA. Os tubos foram centrifugados $(10.000 \mathrm{~g})$ e os sobrenadantes aplicados em colunas contendo $0,6 \mathrm{~mL}$ de resina de troca iônica (tipo aniônica forte, Dowex AG 50X-8). As colunas foram lavadas com $1 \mathrm{~mL}$ adicional de tampão HEPES e os eluatos foram combinados aos anteriores para posterior contagem de radioatividade em espectrômetro de cintilação, após a adição de $10 \mathrm{~mL}$ de líquido de cintilação.

As leituras foram corrigidas por subtração dos valores de radioatividade obtidos na presença de 1 mM de L-NAME (inibição específica para a conversão da $\left[{ }^{3} \mathrm{H}\right] \mathrm{L}$-arginina para $\left[{ }^{3} \mathrm{H}\right] \mathrm{L}-\mathrm{citrulina}$ dependente de NOS). Para o cálculo das atividades enzimáticas, as leituras corrigidas (em desintegrações por minuto, dpm) foram relacionadas à leitura da $\left[2,3,4,5-{ }^{3} \mathrm{H}\right] \mathrm{L}$-arginina mono hidrocloreto adicionada diretamente no vial de cintilação (sem passagem através da coluna $d$ etroca iônica):

\section{$\mathrm{pmol}$ L-cit/min $=1000 \times\left(\left(\mathrm{dpm}_{\text {amostra }}-\mathrm{dpm}\right.\right.$ L-NAME $) / \mathrm{dpm}_{\text {totais }} / 30$}

onde 1000 foi a quantidade de L-arginina adicionada à mistura de incubação (em pmols) e 30 foi o tempo de incubação (em min).

A fim de caracterizar o tipo de NOS, foi realizado em paralelo controle farmacológico da atividade enzimática que consistiu na omissão do $\mathrm{CaCl}_{2}$ e na adição de $1 \mathrm{mM}$ de EGTA no meio de incubação.

O conteúdo de proteínas foi determinado pelo método de Bradford (1977) e a atividade da NOS foi expressa como pmols de L-citrulina produzidos por minuto e por mg de proteína.

\subsection{Estudo Farmacocinético da Rosiglitazona}

\subsubsection{Tratamento}

Quarenta e cinco animais foram divididos em dois grandes grupos, Vinte e cinco animais receberam rosiglitazona comercial (Avandia) por via oral e vinte animais receberam sal puro de rosiglitazona por via intraperitoneal ambos na dose de $10 \mathrm{mg} / \mathrm{kg}$. Os dois grandes grupos foram divididos em sub-grupos (4 - 5 animais) os quais foram eutanasiados em tempos previamente definidos para coleta de amostras de sangue após a administração da rosiglitazona: 1, 2, 4, 10 e 24 horas. As amostras de sangue ( $5-6 \mathrm{ML})$ foram coletadas em tubos contendo heparina sódica, centrifugadas (2500 g durante 15 minutos) e o plasma foi separado e imediatamente congelado para a futura quantificação das concentrações de rosiglitazona pelo método de cromatografia líquida de alta eficiência acoplado a espectrometria de massa em Tandem (HPLC -MS/MS). 
Quatro mililitros de solvente de extração (éter etílico/hexano 80/20;v/v) foram adicionados a $200 \mu \mathrm{L}$ de plasma e vortexeado por 40 segundos. Após esse tempo as amostras foram centrifugadas durante 2 minutos a $6000 \mathrm{~g}$ e depois congeladas em freezer $-80^{\circ} \mathrm{C}$. Trinta minutos depois, a fase orgânica foi separada e submetida à evaporação sob fluxo de nitrogênio a $40^{\circ} \mathrm{C}$. $\mathrm{O}$ extrato seco foi ressuspenso com $0,2 \mathrm{~mL}$ de acetonitrila/água (50/50; v/v) e em seguida agitadas em vortex por 10 segundos e transferidas para os viais do auto-injetor.

\subsubsection{Validação Pré-Estudo}

Como descrito acima, a técnica analítica utilizada foi a de HPLC-MS/MS após extração líquidolíquido do analito das amostras de plasma. 0 método de detecção foi por monitoramento de reação múltipla (MRM) com o limite de detecção (LOD) e o limite inferior de quantificação (LLOQ) determinado calculando as concentrações com uma relação sinal-ruído maior que 7. O limite de quantificação (LOQ) do método foi de $1 \mathrm{ng} / \mathrm{ml}$, com faixa linear de quantificação entre 1 e $500 \mathrm{ng} / \mathrm{ml}$. 0 parâmetro de quantificação foi a resposta (área do analito - $\mathrm{x}$ ) calculando a concentração pelo uso da equação: $y=a$ $+b x+c x^{2}$ (ponderado usando 1/x como fator de peso). As amostras que serviram como controle de qualidade (QCs) do ensaio foram definidas nas concentrações equivalentes a 3 (nível baixo), 80 (nível médio) e $400 \mathrm{ng} / \mathrm{mL}$ (nível alto). 


\subsubsection{Descrição Geral das Condições Cromatográficas}

Foi utilizado um sistema de HPLC (Agilent G1312A Series, USA) consistindo em uma bomba quaternária (G1322-A), um controlador G1322A (Agilent, EUA) e um auto injetor HST-Pal (Agilent, EUA), acoplado a um espectrômetro de massas Quattro IC (Micromass, England).

A coluna analítica usada foi uma Genesis C18, $4 \mu \mathrm{m}(100 \times 4,5 \mathrm{~mm})$. A composição da fase móvel foi uma mistura de acetonitrila:água (70:30; v/v) adicionada de $0.1 \%$ ácido fórmico e $10 \mathrm{mM}$ de amônia, e foi bombeada a $250 \mu \mathrm{L} / \mathrm{min}$ (sendo que $50 \%$ deste fluxo entrava no espectrômetro). 0 tempo total de corrida foi de 5 minutos. 0 volume de injeção foi de $20 \mathrm{uL}$ e 0 autoinjetor operada em temperatura ambiente $\left(20 \pm 2{ }^{\circ} \mathrm{C}\right)$. 0 sistema tandem MS-MS utilzado era do tipo Turbo-ion-spray® com a fonte operando em modo de ionização positiva (ESI+) e operado pelo software Masslynx v 3,5 (Micromass, Reino Unido).

\subsubsection{Parâmetros de detecção}

O espectometro de messa foi previamente calibrado com o alcance de $20-1000 \mathrm{~m} / \mathrm{z}$, de acordo com a especificação do fornecedor. A calibração do instrumento foi feita pela infusão continua de rosiglitazona (1 $\mu \mathrm{g} / \mathrm{mL})$. 0 monitoramento de reação múltipla (MRM) foi definida para a transição de íons como segue: $\mathrm{m} / \mathrm{z}=358.1-135.4$. O "dwell time" foi de $0.3 \mathrm{~ms}$, a resolução da massa foi de 1 unidade, o tempo de retenção foi de 0.72 minutos, a energia de colisão foi de $8 \mathrm{eV}$ e o potencial dessolvatação foi de $25 \mathrm{~V}$. A temperatura da fonte foi ajustada para $500^{\circ} \mathrm{C}$.

\subsubsection{Validação do método analítico}

Antes de proceder às análises das amostras, um conjunto de procedimentos foram executados para validar cada corrida analítica. Estes incluiram a avaliação da presença de substâncias interferentes, ajuste das curvas de calibração e determinação do limite de quantificação (LOQ) do método. 
3.9 Análises bioquímicas de marcadores da funç o renal e hepática

As atividades enzimáticas circulantes de aspartato amina transaminase (AST) e gama glutamil transferase $(\gamma-G T)$ foram determinadas como marcadores de função hepática. As concentrações séricas de creatinina e uréia foram determinadas como marcadores de função renal. Todas as dosagens foram realizdasa empregando kits comerciais (Labtest, SP).

3.10 Análises bioquímicas de marcadores da atividade óssea

As atividades enzimáticas circulantes de fosfatase alcalina e fosfatase ácida resistente a tartarato (TRAP) foram determinadas como marcadores da atividade de osteoblastos e osteoclastos, repectivamente. As concentrações séricas de cálcio foram determinadas como um marcados da atividade óssea. Todas as dosagens foram realizadas empregando kits comerciais (Labtest, SP).

\subsection{Análise estatística}

Diferenças entre os grupos foram analisados pela análise da variância (ANOVA) de uma via seguido do teste de Student-Newman Keuls para múltiplas comparações empregando o programa Prisma GraphPad. Em casos que foram comparados somente 2 grupos foi utilizados Teste $t$ (nāo paramétrico) selecionado no programa Prisma GraphPad. Os resultados são apresentados como média \pm SEM. 


\section{RESULTADOS}

\subsection{Análise da perda óssea alveolar}

A Figura 6 demonstra a medida em milímetros doa junção cemento-esmalte a crista óssea alveolar em radiografias de mandíbulas de animais Sham e com periodontite, periodontite tratados com CMC, Avandia, DMSO e sal puro de rosiglitazona, 7 dias após a indução da periodontite. Diferenças significativas na medida da perda óssea alveolar foram observadas quando comparado o grupo de animais com Periodontite $(1 \pm 0.05)$ com os grupos de animais tratados com DMSO $(0.7 \pm 0.02, p<0.001$, $\mathrm{n}=10$ para cada grupo), e CMC $(0.9 \pm 0.05, p<0.05, n=10$ para cada grupo) e quando comparamos os animais do grupo tratado com DMSO com o grupo de animais tratados com Rosiglitazona $(0.7 \pm 0.02 \mathrm{vs}$ $0.9 \pm 0.02, p<0.05, n=10$ respectivamente).

A Figura 7 demonstra a medida em milímetros doa junção cemento-esmalte a crista óssea alveolar (JCE/COA) em radiografias de mandíbulas de animais com periodontite tratados com DMSO e Lipanon, 7 dias após a indução da periodontite. Observamos aumento significativas da medida JCE/COA quando comparamos os grupos periodontite como grupo Lipanon (0.88 \pm 0.07 vs. $1.11 \pm 0.06$, $p<0.01, n=10$ para cada grupo).

4.2 Reação em cadeia da polimerase - transcriptase reversa em tempo real (qPCR)

Na Tabela 1, temos resultados de qPCR para a expressão gênica de eNOS, nNOS, iNOS, PPAR $\alpha$, PPAR $\beta$ and PPAR 7 dias após a indução da periodontite em osso alveolar de animais Sham comparados a animais com periodontite, animais com periodontite tratado com CMC comparado a animais tratados com Avandia (10 mg/kg/day) e aniamais tratatdos com DMSO comparados a animais tratados com sal puro de rosiglitazona (10 mg/kg/day) ambos com periodontite. Observamos aumento significante da expressão gênica de iNOS em animais do grupo Avandia quando comparado ao grupo de animais tratados com CMC (25.5 \pm 4.9 VS $1, P<0.05, n=7$ para cada grupo) e em animais do grupo Rosiglitazona quando comparado ao grupo de animais tratado com DMSO $(3.4 \pm 0.7$ VS $1, P<0.05, n=7$ para cada grupo). Já a expressão gênica de nNOS, observamos aumento no grupo de animais rosiglitazona quando comparado aos animais DMSO (12.2 \pm 2.1 VS $1, P<0.05, n=8$ para cada grupo). Já 
a expressão gênica de PPAR- $\alpha$, observamos diminuição nos grupos de animais com periodontite quando comparado aos animais Sham $(0.05 \pm 0.002$ VS $1, P<0.02, n=8$ para cada grupo). Na expressão gênica de PPAR- $\gamma$, observamos diminuição no grupo de animais com periodontite quando comparado ao grupo de animais do grupo Sham $(0.08 \pm 0.01$ VS $1, P<0.05, n=8$ para cada grupo) e aumento no grupo de animais rosiglitazona quando comparado ao grupo de animais DMSO (4.6 \pm 0.8 VS $1, P<0.05$, $\mathrm{n}=8$ para cada grupo). Não observamos alterações significativas na expressão gênica de eNOS entre os diferentes grupos.

A Tabela 2 mostra resultados de qPCR para a expressão gênica de RANKL, TRAF6, TRAF2, RUNX2 e OSTERIS, 7 dias após a indução da periodontite, em amostras de osso alveolar de animais Sham comparados a animais com periodontite, animais com periodontite tratado com CMC comparado a animais tratados com Avandia e animais tratados com DMSO comparados a animais tratados com sal puro de rosiglitazona todos com periodontite. Não houve diferença estatística significativa na expressão gênica de RANKL e RUNX2 entre os diferentes grupos. Contudo, na expressão gênica de TRAF2, observamos diminuição significativa no grupo de animais tratados com Avandia quando comparado aos animais tratados com CMC $(0.01 \pm 0.1$ VS $1, P<0.001, n=8$ para cada grupo) e quando comparamos os grupos DMSO e Rosiglitazona puro $(0.001 \pm 0.001$ VS $1, P<0.05, n=8$ para cada grupo). Observamos significante queda a expressão gênica de Osterix no grupo tratado com sal puro de rosiglitazona quando comparado ao grupo tratados com DMSO (0.05 \pm 0.01 VS $1, P<0.001, n=8$ para cada grupo). Já a expressão de TRAF6, observamos aumento significativo na expressão gênicano grupo Rosiglitazona puro quando comparado ao grupo DMSO ( $5 \pm 0.2$ VS $1, P<0.05, n=8$ para cada grupo)

\subsection{Farmacocinético da Rosiglitazona}

A Figura 8 mostra a farmacocinética da rosiglitazona em ratos vinte e quatro horas após administração de doses únicas e da vigésima primeira dose das duas fontes utilizadas (Avandia comercial por via oral e maleato de rosiglitazona puro por via intraperitoneal) na dose de $10 \mathrm{mg} / \mathrm{kg} / \mathrm{dia}$. Os resultados são apresentados em nanogramas por mililitro. Observamos diferença significativa entre a concentração plasmática de rosiglitazona V.O quando comparado a concentração plasmática I.P na primeira hora após a aplicação da dose $(20,43 \pm 2,02$ VS $9,47 \pm 4,5, P<0,05, n=4$ a 5 para cada grupo). A análise do tempo de meia vida da rosiglitazona revelou um $T_{1 / 2}$ de $\sim 6$ horas para 0 Avandia e $\sim 12,7$ horas para o sal puro de rosiglitazona. Não observamos alterações significativas entre os presentes grupos após a vigésima primeira dose. 


\subsection{Atividade da NOS}

A Figura 9 mostra resultados da atividade da óxido nítrico sintase dependente de cálcio (painel A) e independente de cálcio (panel B) em homogenatos de pulmão de grupo de animais não tratados (CONT and LPS) e tratados com DMSO (LPS+DMSP) 16 horas após a injeção de LPS. No painel A foi observado aumento significativo na atividade da NOS dependente de $\mathrm{Ca}^{2+}$ em grupo de animais que receberam LPS $(0.45 \pm 0.14 p<0.05, n=6)$ e LPS com DMSO $(0.49 \pm 0.09 p<0.05, n=6)$ ambos quando comparados ao grupo controle $(0.06 \pm 0.004 p<0.05, n=6)$. No painel $B$, observamos aumento significativo da atividade da NOS independente de $\mathrm{Ca}^{2+}$ quando comparamos 0 grupo de animais controle com os grupos de animais que receberam LPS $(0.06 \pm 0.003$ vs $3.57 \pm 0.27, p<0.001, n=6$ para cada grupo) e DMSO ( $2.73 \pm 0.34$ vs. $0.06 \pm 0.03, p<0.001, n=6$ para cada grupo). Houve diminuição da atividade da NOS independente de $\mathrm{Ca}^{2+}$ quando comparamos o grupo que recebeu LPS e foi tratado com DMSO com o grupo que recebeu somente LPS $(2.73 \pm 0.34$ vs. $3.57 \pm 0.27, p<0.05, n=6$ para cada grupo).

\subsection{Análise bioquímica de marcadores da atividade óssea}

A Figura 10 mostra resultados de níveis séricos de cálcio (painel A), fosfatase alcalina (painel B) e fosfatase ácida tartarato resistente (TRAP)[painel C] respectivamente em plasma de animais Sham (SH) e com periodontite tratados com CMC, DMSO, Avandia e sal puro de rosiglitazona 7 dias após a indução de periodontite. Observamos diferenças significativas nos níveis de cálcio entre os animais dos grupos tratados com sal puro de rosiglitazona quando comparado aos animais dos grupos Sham $\left(7,5 \pm 0,89\right.$ VS $11.00 \pm 0,20{ }^{* * *} P<0,001 \quad n=4$. respectivamente), CMC $(7,5 \pm 0,89$ VS $10,84 \pm 0,19$ ${ }^{* * *} \mathrm{P}<0,001 \mathrm{n}=4$. respectivamente), Avandia (7,5 $\pm 0,89$ VS $10 \pm 0,22{ }^{* * *} \mathrm{P}<0,001 \mathrm{n}=4$. respectivamente) e DMSO $(7,5 \pm 0,89$ VS $8,46 \pm 1,83 \# \#<<0,01 \mathrm{n}=4$. respectivamente). Não observamos diferenças significativas quando comparamos os diferentes grupos em relação aos resultados de fosfatase alcalina e TRAP. 
4.6 Análise bioquímica de marcadores da atividade renal e hepática

$\mathrm{Na}$ Tabela 3 são mostrados os resultados das análises das atividades de AST e $\gamma$-GT, e concentrações de creatinina e uréia em soro ou plasma. Não houve alterações significativas quando comparados os diversos grupos. 
Figura 6 - Valores da distância da JCE à crista óssea alveolar (em $\mathrm{mm}), 7$ dias após a indução da periodontite, em animais Sham e com peridontite (PERIO), animais com periodontite tratados com CMC (veículo do Avandia), Avandia, DMSO (veículo do sal puro de rosiglitazona) e sal puro de rosiglitazona (ROSIG).

\section{JCE/COA}

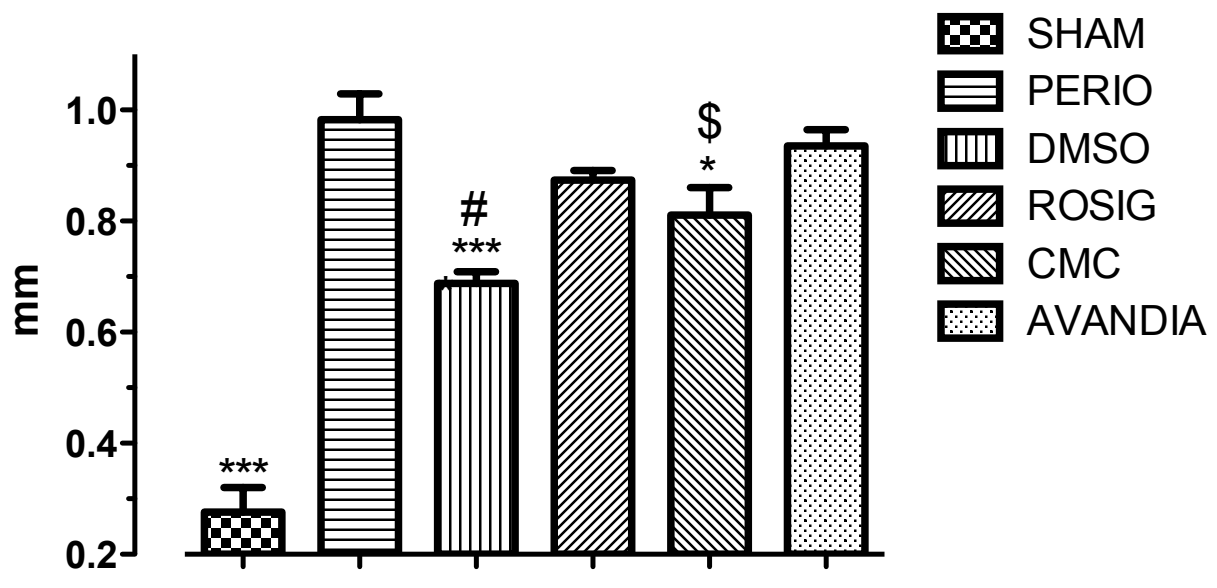

Os dados foram analisados estatisticamente pelo teste $t$ de student e são expressos como média \pm SEM para $n=9$. ${ }^{* * *} \mathrm{P}<0.001$ vs PERIO; ${ }^{*} \mathrm{P}<0.05$ vs PERIO; \# $\mathrm{P}<0.05$ vs ROSIG; $\$ \mathrm{P}<0.05$ vs Avandia.

Fonte: Martins Porto R (2012) 
Figura 7 - Valores da distancia da JCE a crista óssea alveolar (em $\mathrm{mm}), 7$ dias após a indução da periodontite em animais com periodontite tratados com CMC e Lipanon.

\section{JCE/COA}

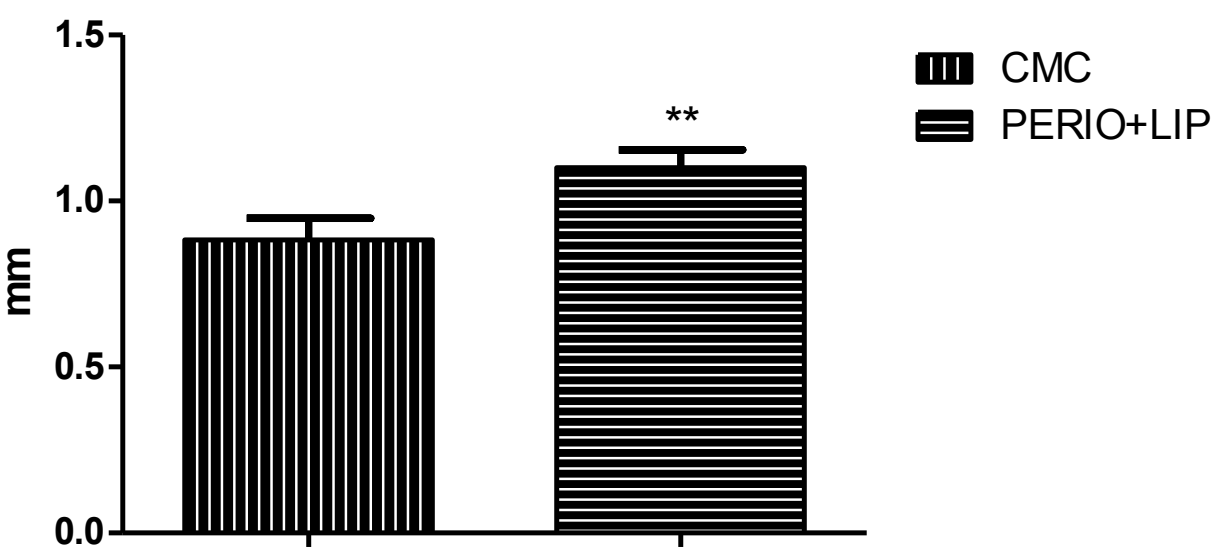

Os dados foram analisados estatisticamente pelo Teste $\mathrm{t}$ (nāo paramétrico) e estão expressos como média \pm SEM para $n=$ 6. ${ }^{* *}<0.01$ vs $C M C$.

Fonte: Martins-Porto R (2012) 
Tabela 1 - Expressão gênica por qPCR para as isoformas de NOS e PPAR em amostras de osso alveolar, 7 dias após a indução da periodontite em animais do grupo Sham e periodontite, periodontite tratado com CMC (veículo do Avandia) e Avandia, DMSO (veículo do sal puro de rosiglitazona) e sal puro de rosiglitazona.

\begin{tabular}{lrl|cl|cc}
\hline Por Genes & \multicolumn{1}{c}{ Sham } & \multicolumn{1}{c}{ Perio } & CMC & AVANDIA & DMSO & ROSIG \\
iNOS & - & - & 1 & $25.5 \pm 1.5^{*}$ & 1 & $3.4 \pm 0.7^{\#}$ \\
eNOS & 1 & $0.2 \pm 0.2$ & 1 & $2.4 \pm 7.4$ & 1 & $2.2 \pm 9.9$ \\
nNOS & 1 & $0.3 \pm 0.09$ & 1 & $1.1 \pm 0.1$ & 1 & $12.2 \pm 42.5^{\#}$ \\
PPARa & 1 & $0.05 \pm 0.002^{\& \&}$ & 1 & $1.3 \pm 13.7$ & 1 & $0.5 \pm 0.1$ \\
PPARy & 1 & $0.08 \pm 0.01^{\&}$ & 1 & $0.9 \pm 0.07$ & 1 & $4.6 \pm 0.8^{\#}$ \\
PPAR $\beta$ & - & - & 1 & $10.5 \pm 1.3^{*}$ & 1 & $0.9 \pm 0.3$ \\
\hline
\end{tabular}

Os resultados são expressos relativos ao grupo Sham, DMSO e CMC. Foram analisados estatisticamente pelo Teste t (nāo paramétrico) e expressos como média $\pm \mathrm{SEM} ; n=7-8$ animais por grupo. ${ }^{\circledR} \mathrm{P}<0.05$ vs Sham, ${ }^{*} \mathrm{P}<0.05$ vs $C M C,{ }^{\# P}<0.05$ vs DMSO, \&\&P $<0.01$ vs Sham.

Fonte: Martins-Porto R (2012) 
Tabela 2 - Expressão gênica por qPCR para RANKL, TRAF6, TRAF2, RUNX2 and OSTERIX em amostras de osso alveolar, 7 dias após a indução da periodontite, em animais do grupo Sham e periodontite, periodontite tratado com CMC (veículo do Avandia) e Avandia, DMSO (veículo do sal puro de rosiglitazona )e sal puro de rosiglitazona.

\begin{tabular}{|c|c|c|c|c|c|c|}
\hline \multirow[t]{2}{*}{ Genes } & \multicolumn{6}{|c|}{ Groups } \\
\hline & Sham & Perio & CMC & AVANDIA & DMSO & ROSIG \\
\hline RANKL & 1 & $0.4 \pm 0.1$ & 1 & $0.8 \pm 0.1$ & 1 & $1.5 \pm 2.2$ \\
\hline TRAF6 & 1 & $15.4 \pm 1.8$ & 1 & $0.7 \pm 0.1$ & 1 & $5 \pm 0.2^{*}$ \\
\hline TRAF2 & - & - & 1 & $0.1 \pm 0.1^{* * *}$ & 1 & $0.0 \pm 0.0 \$ \$$ \\
\hline RUNX2 & 1 & $1.6 \pm 3.9$ & 1 & $1.45 \pm 0.3$ & 1 & $1 \pm 0.3$ \\
\hline OSTERIX & 1 & $0.93 \pm 0.2$ & 1 & $0.9 \pm 0.3$ & 1 & $0.05 \pm 0.01$ \\
\hline
\end{tabular}


Figura 8 - Curva farmacocinética da rosiglitazona em ratos 24 horas após a administração de dose única e da vigésima primeira dose (10 mg/kg) de Avandia (V.O) ou maleato de rosiglitazona puro (I.P).

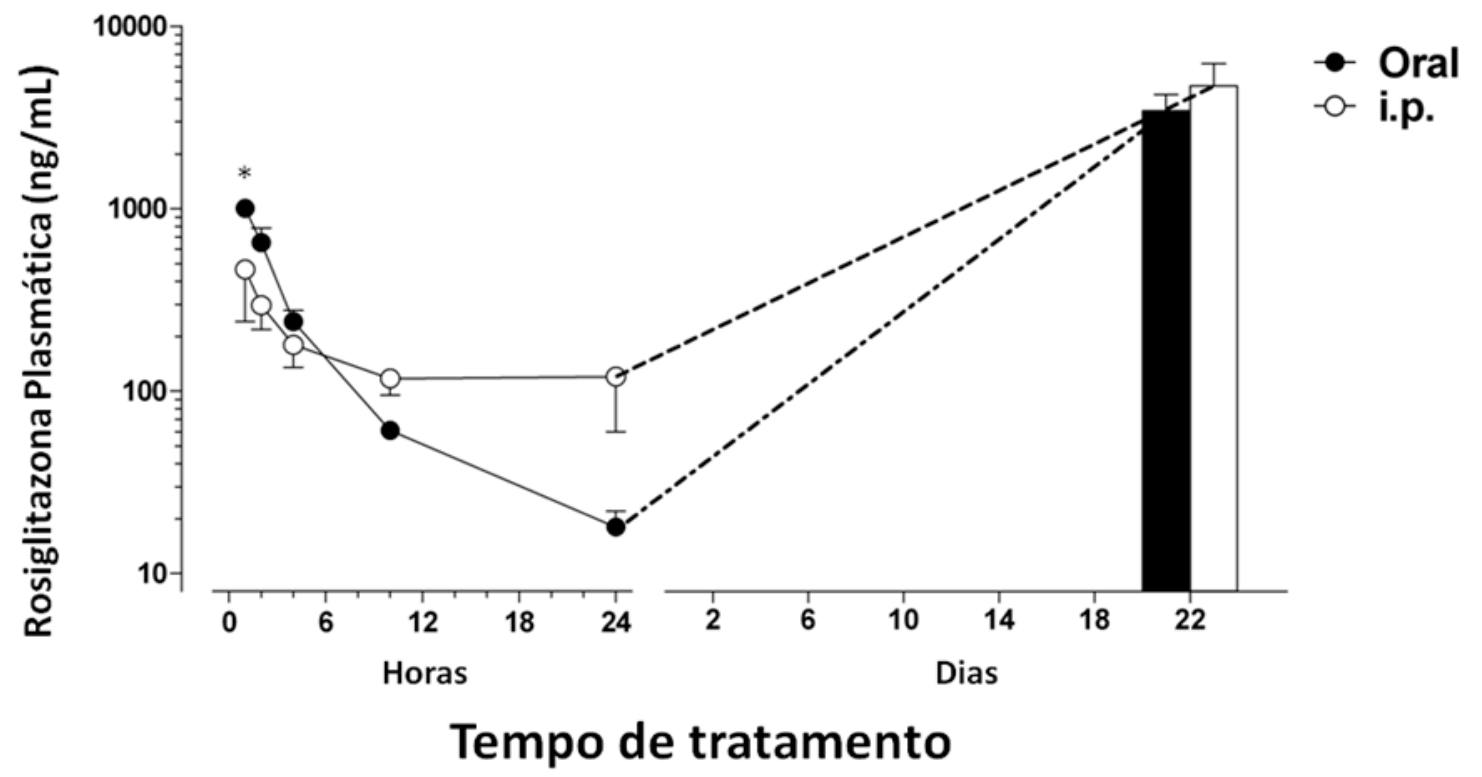

Os dados foram analisados estatisticamente pelo Teste $t$ (nāo paramétrico) e estão expressos como média \pm SEM para $n=$ 6. ${ }^{*} \mathrm{P}<0,05$ vs IP.

Fonte: Martins-Porto R (2012) 
Figura 9 - Avaliação da atividade da NOS presente em homogenates de pulmão de ratos 16 horas após a injeção de LPS. Painel A mostra a atividade da NOS dependente de cálcio e painel B mostram a atividade da NOS independente de Cálcio.

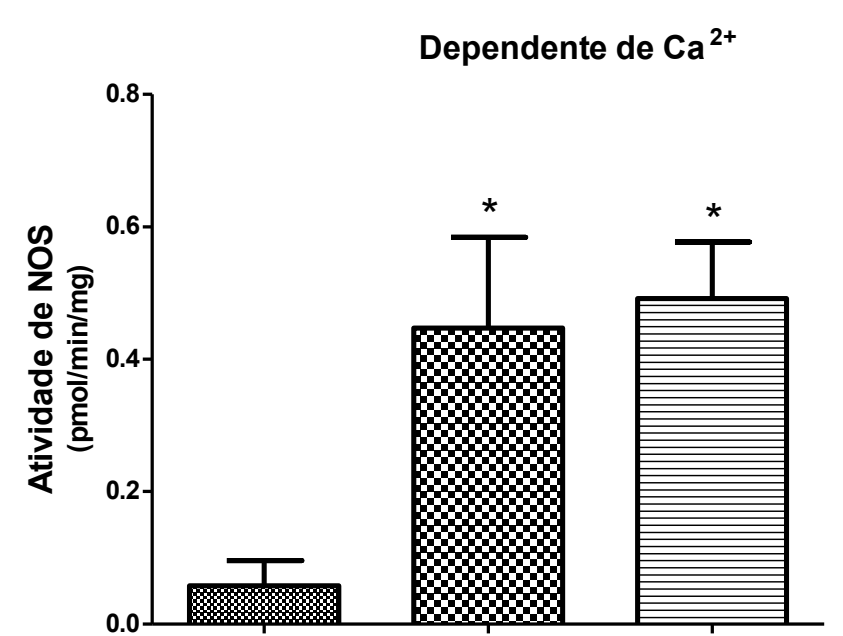

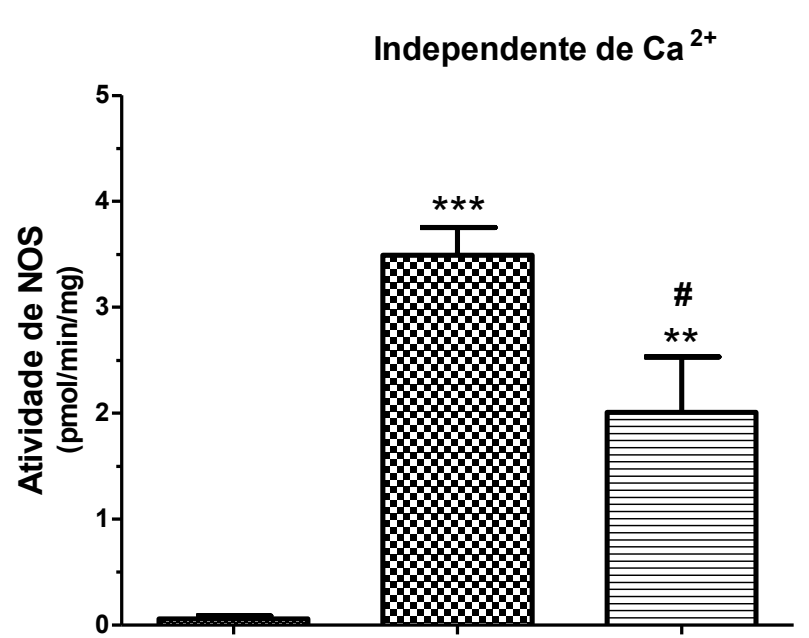

\section{田 LPS}

Os dados foram analisados estatisticamente pelo teste t de student e são expressos como média \pm SEM para $n=5-7 .{ }^{*} P<0.05$ vs CONT, ${ }^{* *} P<0.01$ vs CONT, ${ }^{* * *} P<0.001$ vs CONT, \# $P<0.05$ vs LPS.

Fonte: Martins Porto R (2012) 
Figura 10 - Concentrações séricas de cálcio (painel A), atividades plasmáticas de fosfatase alcalina (painel B) e fosfatase ácida tartarato resistente (TRAP) [painel C] medidas nos grupos de ratos Sham $(\mathrm{SH})$ ou com periodontite tratados com CMC (veículo do Avandia), DMSO (veículo do sal puro de rosiglitazona), Avandia e sal puro de rosiglitazona (Rosig Puro) 7 dias após a indução da doença.

A.

Cálcio
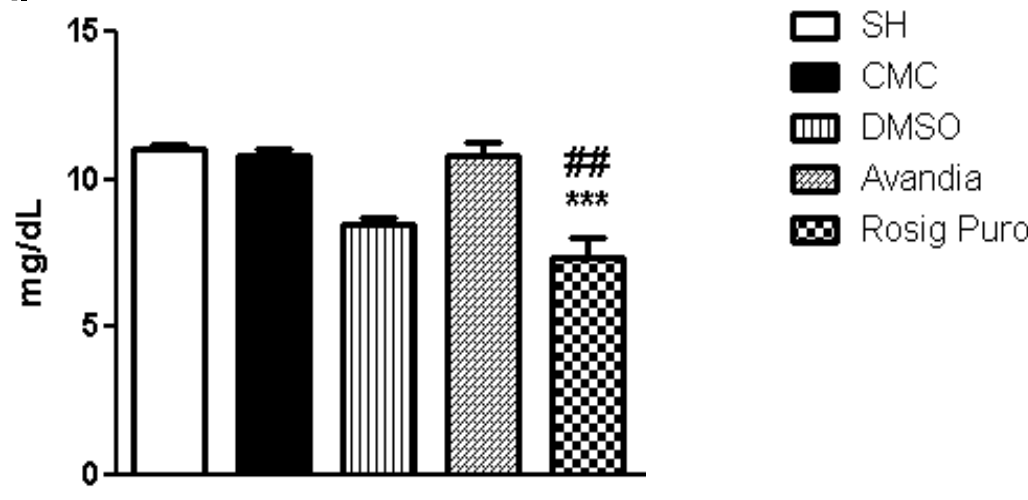

B. Fosfatase Alcalina
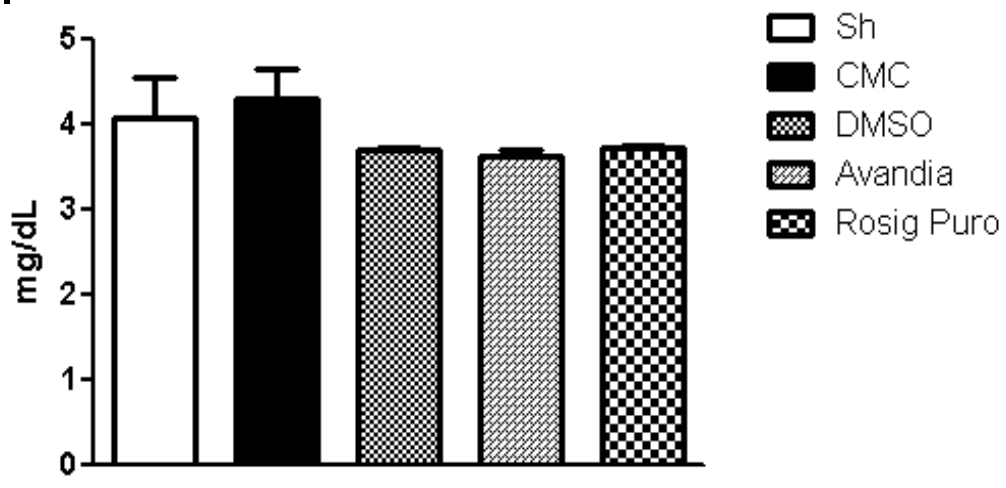

C.

TRAP
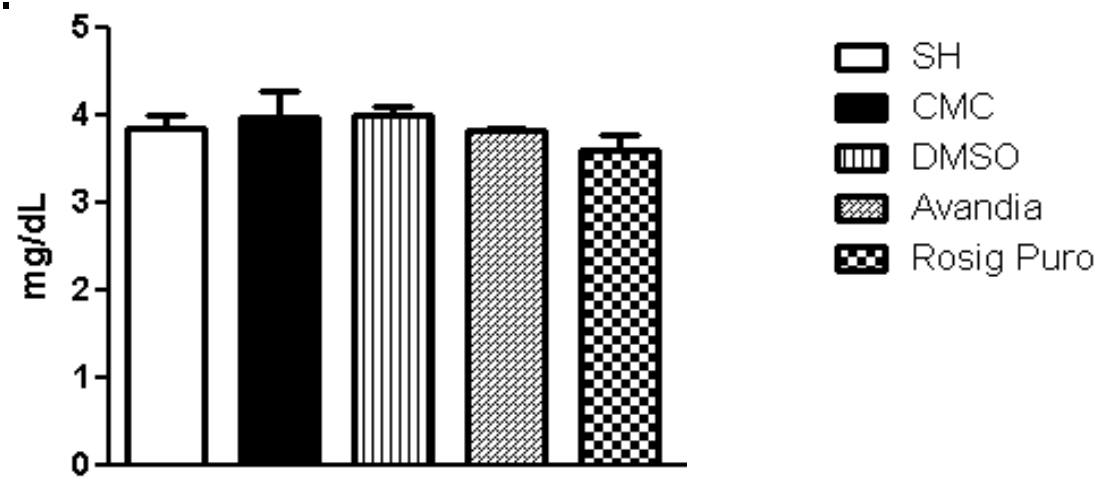

Os dados foram analisados estatisticamente pelo teste $t$ de student e são expressos como média \pm SEM para $n=5$. ${ }^{* * *} \mathrm{P}<0,001$ vs SHAM,CMC, Avandia; \#\# P<0,01vs DMSO.

Fonte: Martins Porto R (2012) 
Tabela 3 - Parâmetros bioquímicos médios em plasma ou soro de ratos Sham, com periodontite e com periodontite tratados com CMC (veículo do Avandia), Avandia, DMSO (veículo do sal puro de rosiglitazona) e sal puro de rosiglitazona 7 dias após a indução da doença.

\begin{tabular}{|c|c|c|c|c|c|c|}
\hline \multirow[t]{2}{*}{ Genes } & \multicolumn{6}{|c|}{ Groups } \\
\hline & Sham & Perio & CMC & AVANDIA & DMSO & ROSIG \\
\hline AST & $27.3 \pm 5.1$ & $24 \pm 1$ & $28.5 \pm 4$ & $27.3 \pm 3$ & $29.4 \pm 2.7$ & $31 \pm 2.1$ \\
\hline$\gamma$-GT & $57.5 \pm 12$ & $64 \pm 7$ & $26 \pm 10$ & $58 \pm 3.5$ & $52 \pm 8$ & $25 \pm 5.5$ \\
\hline CREATININA & $14 \pm 1.5$ & $10.5 \pm 3.7$ & $14 \pm 0.5$ & $11.5 \pm 1.4$ & $11.6 \pm 0.1$ & $14.8 \pm 2.6$ \\
\hline UREIA & $53.4 \pm 7.7$ & $54.4 \pm 6$ & $66.8 \pm 18$ & $61 \pm 14$ & $45.6 \pm 10$ & $53 \pm 6$ \\
\hline
\end{tabular}

Os dados foram analisados estatisticamente pelo teste t de student e são expressos em $\mathrm{mg} / \mathrm{dL}$ como média \pm SEM, para $\mathrm{n}=5$.

Fonte: Martins Porto R (2012) 


\section{DISCUSSÃO}

A classe de drogas tiazolidinodionas (TZDs) foi aprovada para o uso clínico no tratamento do Diabetes do tipo II em 1999 (Lecka-Czermik at al., 2006). Desde então uma série de efeitos colaterais vem sendo observados em pacientes submetidos ao tratamento crônico com esses medicamentos. Um dos efeitos colaterais mais prevalentes devido ao uso crônico em humanos é a fragilidade óssea (Grey et al., 2008; Wan et al., 2007; Shuartz et al., 2006; Khan et al., 2006). No entanto, efeitos colaterais relacionados a doenças isquêmicas, tais como: infarto do miocárdio, insuficiência cardíaca, parada cardíaca, derrames, isquemia do miocárdio fez a Agencia Nacional de Vigilância Sanitária (ANVISA), por meio do RE N ${ }^{0} 4.466 / 2010$ cancelar o registro do medicamento Avandia em 29 de setembro de 2010.

Com o objetivo de avaliar a influência do tratamento com o sal puro de rosiglitazona (i.p) e Avandia (v.o) na evolução da periodontite induzida em ratos 7 dias após a indução da periodontite, avaliamos a perda óssea alveolar decorrente da periodontite, bem como estudamos a expressão gênica dos fatores transcricionais envolvidos na diferenciação e ativação das células ósseas (RUNX2, Osterix, RANKL, TRAF6, TRAF2) além da expressão gênica das óxido nítrico sintases (iNOS, nNOS e eNOS) e das isoformas dos receptores PPAR (PPAR- $\alpha$, PPAR-ß e PPAR- $\gamma$ ) todos por qPCR.

De acordo com os presentes resultados, observamos que o tratamento com sal puro de rosiglitazona e com Avandia aumentou a perda óssea decorrente da periodontite quando comparado aos animais que receberam os respectivos veículos (Figura 6). No entanto, esses resultados não estão de acordo com os resultados obtidos por Di Paola et al (2006) e por Hassumi et al (2009). Mesmo considerando algumas diferenças metodológicas do segundo trabalho, esses dois trabalhos demonstram que o tratamento tanto com o sal puro de rosiglitazona $(10 \mathrm{mg} / \mathrm{kg} / \mathrm{dia}$, i.p) quanto com a droga comercial Avandia (10 mg/kg/dia, v.o) diminui a perda óssea alveolar secundária à periodontite devido a ação antiinflamatória e diminuição da expressão protéica de RANKL. Voltando a Figura 6, se considerarmos como controle o grupo de animais com periodontite que não receberam os veículos (PERIO), observamos uma grande tendência de diminuição de perda óssea causada pelo tratamento tanto com sal puro de rosiglitazona quanto com Avandia. É evidente que se considerarmos o grupo periodontite sem nenhum tratamento como controle, estaremos cometendo um erro metodológico, pois, levando em consideração a própria Figura 6, podemos afirmar que os veículos utilizados no presente protocolo estão interferindo significativamente na evolução da doença, isso é confirmado com as diferenças de perda óssea estatisticamente significativa quando comparados os grupos CMC e DMSO ao grupo PERIO. 
Revisando a literatura sobre as propriedades dos veículos usados em nossos protocolos, observamos alguns trabalhos que mostram que o DMSO, possui propriedades anti-inflamatórias principalmente por sua capacidade anti-oxidante (Chang et al.,1998; Essany et al.,1997). O DMSO tem sido usado na clínica médica para tratar doenças gastro-intestinais, edemas cerebrais, desordens músculo-esqueléticas, doenças reumatológicas, doenças dermatológicas entre outras (Santos et al.,2003). Chang et al.(2001) utilizando modelo de sepse induzido por peritonite, demonstraram que 0 DMSO age impedindo a ativação do NF-kB e do fator transcricional AP-1 causando diminuição da expressão gênica da molécula de adesão ICAM-1 que tem um importante papel na migração de neutrófilos que é o principal célula responsável pelo desenvolvimento das lesões que caracterizam a septicemia.

A iNOS desempenha um importante papel tanto na sepse quanto na periodontite e tem na ativação do NF-kB e do AP-1 as principais vias de sinalização para a sua ativação. Demonstramos que tanto a inibição inespecífica das NOS pelo inibidor N $_{w}$-nitro L-arginina metilester (L-NAME) como a inibição específica da iNOS pelo mercaptoetilguanidina (aminoguanidina) diminui a perda óssea alveolar decorrente da periodontite em nosso modelo de periodontite induzida em ratos (Herrera et al.,2010; Herrera et al.,2011). Para verificar tal hipótese, induzimos septicemia em ratos (tratados e não tratados com DMSO) com aplicação intravenosa de LPS e verificamos a atividade das NOSs em pulmão desses animais. Observamos que o tratamento com DMSO diminuiu a atividade das NOS independente de cálcio (Figura 9, painel B). É importante comentar que a maioria dos trabalhos da literatura que demonstram a ação anti-inflamatória da rosiglitazona utilizam o dimetilsulfóxido como veículo e apontam para a inibição do NF-kB como o principal mecanismo que explica essa ação. De fato, o trabalho de Di Paola et al (2006) utilizou o DMSO 10\% como veículo e mostrou diminuição da expressão protéica da iNOS e conseqüente diminuição da perda óssea em animais tratados com o sal puro de rosiglitazona quando comparados aos grupos de animais que receberam apenas o veiculo. Como comentado anteriormente, observamos aumento de perda óssea no grupo tratado com o sal puro de rosiglitazona quando comparado ao grupo tratado com DMSO (Figura 6). Como mostrado na Tabela 1, tanto o tratamento com Avandia como com o sal puro de rosiglitazona aumenta a expressão gênica da iNOS, no entanto é visível a ação do DMSO atenuando esse aumento que, apesar de ser marcante, não foi suficiente para alterar o resultado final. Ainda na tabela 1, observamos aumento da expressão gênica da nNOS nos animais tratados com o sal de rosiglitazona puro. A nNOS produz NO em curtos períodos de tempo e em pequenas quantidades, que podem estar contribuindo para 0 aumento da reabsorção óssea alveolar. Apesar de não descartarmos um somatório de produção de NO, ressalta-se, porém, que a principal fonte de NO na periodontite é a iNOS (Vallance, 2003; Moncada, 1999; Abramson, 2008; Gyurko et al 2005). Observamos diminuição significativa na perda 
óssea alveolar no grupo tratado com CMC em relação ao grupo periodontite e Avandia (Figura 6). Não temos conhecimento de dados da literatura que demonstram alguma ação do CMC em qualquer fase da inflamação. Podemos descartar ação mecânica local do CMC no momento da gavagem, pois não houve diferença entre o grupo com periodontite e o grupo com periodontite que recebeu água por gavagem (resultados não mostrados).

Quando utilizamos com referência os animais com periodontite sem tratamento, podemos afirmar que de alguma maneira o tratamento com rosiglitazona está anulando o efeito benéfico dos veículos sobre a periodontite. Além de suas propriedades antiinflamatórias, é bem documentado a ação da rosiglitazona sobre o metabolismo ósseo seja diminuindo a diferenciação de osteoblasto ou aumentando a atividade de osteoclastos (Wan et.al.,2007; Lecka-Czernik 2010; Lecka-Czernik and Suava 2006; Lazarenko et al., 2010) e por este motivo estudaremos os principais fatores transcricionais envolvidos na diferenciação e ativação de osteoblastos e osteoclastos. Na Tabela 2, observamos uma grande tendência de aumento da expressão gênica de RANKL nos animais tratados com o sal puro de rosiglitazona. O RANKL tem um papel importante na ativação dos osteoclastos, que são as células responsáveis pela reabsorção óssea. Sua presença em processo inflamatório é originada principalmente de leucócitos ativados (Crotti et al. 2002; Hayes et al. 2003) e a ativação do seu receptor (RANK) leva a ativação do fator transcricional TRAF6 que resultará na diferenciação e ativação de osteoclastos (Udagawa 2003). 0 aumento da expressão gênica de TRAF6 (Tabela 2) reforça a ideia de aumento da ativação de osteoclastos nos animais tratados com 0 sal puro de rosiglitazona. Segundo trabalho de Gyurko et al (2005) o aumento da expressão gênica de TRAF6 pode está associada ao aumento da expressão de iNOS. Nesse trabalho os autores demonstraram que animais nocautes para iNOS, com periodontite apresentavam diminuição da expressão gênica de TRAF6. No entanto, de acordo com os nossos resultados, podemos sugerir que o aumento da expressão gênica de TRAF6 não está diretamente associada ao aumento de iNOS, pois observamos uma atenuação do aumento da expressão gênica de iNOS no grupo tratado com sal puro de rosiglitazona (provavelmente causado pela ação do DMSO) quanto comparado ao aumento observado no grupo tratado com Avandia. Podemos sugerir um somatório de ativação de outras vias como, por exemplo, a ativação direta de receptores como o próprio RANKL. O aumento de TRAF6 também pode ser devido a ativação de receptores como o de interleucina 1 e para LPS (receptores toll-like, principalmente o TLR4 e TLR7) envolvidos no processo inflamatório/infeccioso presente na periodontite (Carpenter et al., 2009). A própria transcrição gênica da iNOS é ativada por meio desses receptores. Podemos considerar menos provável o envolvimento dos receptores de TNF- $\alpha$ (TNFR1 e TNFR2) por eles ativarem o fator transcricional TRAF2 que apresentou sua expressão gênica diminuída nos animais tratados tanto com Avandia como com o sal puro de rosiglitazona (Tabela 2). A diminuição da 
expressão gênica do fator transcricional Osterix (Tabela 2) é mais um dado que sugere o aumento da perda óssea alveolar nos animais tratados com o sal puro de rosiglitazona. A diminuição de Osterix pelo tratamento com rosiglitazona e sua relação com o aumento de perda óssea é mostrado no trabalho de Rzonca et al (2004). Osterix é importante para produção de matriz óssea pelos osteoblastos. Células osteogênicas que não apresentavam expressão de Osterix (mas sim de RUNX2) não se diferenciaram em osteoblastos e apresentaram genes específicos para condrócitos como SOX9, SOX5, Col2a1 e Lhh (Nakashisma et al., 2002). Camundongos deficientes de Osterix não apresentaram matriz mineralizada em osso formado por ossificação intramembranosa. Nesses animais os ossos de origem endocondral apresentaram algumas matrizes mineralizadas (Nakashisma et al., 2002). A associação da diminuição de produção de matriz óssea e aumento de atividade osteoclástica tende a acelerar o processo de destruição óssea alveolar.

Observamos aumento de perda óssea em animais tratados tanto com 0 sal puro de rosiglitazona (i.p) quanto com o composto comercial Avandia (v.o). Apesar disso, podemos sugerir que os protocolos de tratamentos estão agindo de maneiras distintas. Nos grupos tratados com o sal puro de rosiglitazona, temos ação em moléculas diretamente envolvidas no metabolismo ósseo como RANKL, TRAF6, Osterix, além do aumento da expressão gênica da eNOS e iNOS. Já o Avandia (v.o), parece agir diretamente na iNOS, isoforma que produz NO por um longo período de tempo e está envolvida na destruição de tecidos por aumentar a síntese de metaloproteinases de matriz, diminuir a síntese de colágeno e proteoglicanos além de aumentar a atividade de osteoclastos (Abramson 2008; Jung et al. 2003; Mancini et al. 1998; Gyurko et al 2005). Trabalhos publicados no final de 2011 demonstram a ação do DMSO sobre os osteoblastos e osteoclastos. Lemieux at al., 2011 demonstraram que o DMSO, em cultura de células, age sobre a diferenciação dos osteoclastos de maneira dependente da concentração: em concentrações próximas a $5 \mu \mathrm{M}$ (equivalente a 5\%) 0 DMSO estimula a diferenciação de osteoclastos. Na concentrações de 10 $\mu \mathrm{M}$ (equivalente a 10\%) 0 DMSO inibe a diferenciação de osteoclastos. Já em concentrações acima de $20 \mu \mathrm{M}$ (equivalente a 20\%) o DMSO causa morte celular. Stephens at al., 2011, também trabalhando com cultura de células, demonstraram que o DMSO aumenta o potencial de mineralização e a diferenciação de osteoblastos humanos via aumento da expressão de RUNX2, Osterix e de um novo fator transcricional (Mef2c). Os autores chamam a atenção para a necessidade de trabalhos que estudem a ação do DMSO sobre 0 metabolismo ósseo in vivo. De acordo com a Figura 10 (painel A) o DMSO diminui os níveis séricos de cálcio nos grupos de animais tratados (apesar de nāo ser estatisticamente significativo) e que essa alteração se agrava na presença da rosiglitazona. Essa hipocalcemia observada na presença da rosiglitazona (Figura 10, painel A) pode ser devido a ação negativa da rosiglitazona sobre os osteoblastos (estimulando as células precursoras a se diferenciarem em adipócito) somado à 
diminuição da atividade dos osteoclastos causada pela ação do DMSO. Essas alterações geram incapacidade do organismo em mobilizar cálcio estocado nos ossos dando origem à hipocalcemia observada em nossos resultados. Outra hipótese que pode explicar o resultado observado na Figura 10 (painel A) é a ideia que o DMSO pode está reagindo com o tecido mineral do osso (por exemplo com a hidróxiapatita) formando cristais modificados e esses novos cristais podem ser mais resistentes à ação dos osteoclastos, isso causaria diminuição dos níveis séricos de cálcio e explicaria o aumento da sinalização gênica para os osteoclastos (organismo tentando compensar a queda dos níveis séricos de cálcio). A rosiglitazona agravaria o quadro diminuindo a quantidade de osteoblastos presentes em toda a estrutura óssea. Essa segunda hipótese baseia-se no trabalho de Stephens et al., (2011) que demonstra que o DMSO aumenta o tecido mineralizado formado pelos osteoblastos e no trabalho de Pasdar et al., 2011 que mostra que o DMSO pode reagir com estruturas em que o cálcio esteja presente. Quanto aos resultados de fosfatase alcalina e TRAP (Figura 10, painéis B e C) não observamos nenhuma alteração, provavelmente, devido ao tempo estudado não ter sido suficiente para que as alterações na sinalização gênica causassem alteraçōes celulares capazes de serem detectadas sistemicamente. Mais estudos serão necessários para descrever o mecanismo pelo qual o DMSO altera o metabolismo do cálcio in vivo e a participação da rosiglitazona nesse processo.

Os diferentes mecanismos de ação da rosiglitazona podem estar ligados a distintas concentrações da droga disponíveis no organismo devido a diferenças farmacocinéticas nas vias de administração. Para responder tal questão, fizemos o estudo cinético dos níveis plasmáticos de rosiglitazona ao longo do tempo. De acordo com a Figura 8, verificamos que a concentração plasmática de rosiglitazona administrada por via oral é maior que a observada por via intraperitoneal na primeira hora. Não existem diferenças estatisticamente significativas em tempos posteriores. Uma possível explicação para esse resultado observado durante a fase de absorção seria a ionização da droga no peritônio resultando em uma liberação lenta de rosiglitazona, chegando a ser mais lenta que a absorção no intestino. Segundo trabalho de Mohan Kamila et al (2009) a solubilidade da rosiglitazona é $\mathrm{pH}$ dependente, a maior solubilidade observada foi em $\mathrm{pH}$ 1,2, caindo gradualmente com o aumento do pH. Acima do pH 6 a solubilidade caiu drasticamente. Levando-se em consideração os resultados do calculo de meia vida da rosiglitazona (6,9 h para Avandia e 12,9 h para rosiglitazona puro), observamos que o sal puro de rosiglitazona está sendo eliminado e/ou metabolizada mais lentamente que 0 Avandia. A meia vida do Avandia está mais próxima ao tempo observado em humanos ( 3 a 4 horas) [Sheen, 2007]. Estudos farmacocinéticos demonstram que a rosiglitazona é metabolizada no fígado por enzimas do citocromo P450 (principalmente pela CYP2C8 e em menor quantidade pela CYP2C9) que agem hidroxilando e n-desmetilando a molécula (Baldwin et al., 1999). Sahi et al.(2003) estudaram a indução e inibição das enzimas da família P450 em cultura de hepatócitos tratados com 
tiazolidinodionas (rosiglitazona, pioglitazona e troglitazona) e observaram que a rosiglitazona, em altas doses, aumentou a atividade e a expressão gênica da CYP3A4 e inibiu a atividade da CYP2CA6 e CYP2B6 não interferindo nas demais enzimas. Não temos conhecimento de dados da literatura que demonstre ação da rosiglitazona sobre sua própria metabolização. Existem trabalhos na literatura que mostram que o DMSO age induzindo as principais enzimas hepáticas, entre elas, a CYP2C8 e a CYP2C9 (Busby et al., 1999; Choi et al., 2009). É pouco provável que o aumento da meia vida do sal puro de rosiglitazona seja devido a alterações do metabolismo hepática, pois tanto o veículo (DMSO) quanto a rosiglitazona agem como indutores das principais enzimas atuantes no fígado. Podemos suspeitar de alteração relacionada à excreção renal, porém, não temos conhecimento, até o momento, de estudos que demonstrem alterações na excreção renal provocada pela própria rosiglitazona. Os animais submetidos aos nossos protocolos experimentais não apresentaram alterações nos marcadores de atividade renal como creatinina e uréia e hepática como AST e Y-GT (Tabela 3). Diante desses resultados podemos concluir que a diferença nos mecanismos de ação observados até o momento não é devido a diferenças farmacocinéticas e sim pela interferência do DMSO.

Surge uma nova questão: Qual será o papel dos receptores PPAR- $\alpha$ e PPAR- $\beta$ nos presentes resultados? Segundo a literatura, todas as três isoformas de PPAR estão envolvidos na inflamação. Normalmente as ativações desses receptores estão associadas a ações antiinflamatórias (Chan et al., 2010; Dinarello 2010, Di Paola et al. 2007; Kawahito et al., 2000). Poder-se-ia esperar um aumento da expressão gênica das três isoformas dos PPARs no osso alveolar de animais com periodontite em uma tentativa de o organismo controlar o processo inflamatório. No entanto, observamos que a expressão gênica de PPAR- $\alpha$ e PPAR- $\beta$ (Tabela 1) estão diminuídas nos grupos de animais com periodontite. Não foi observada expressão gênica de PPAR- $\beta$ em animais do grupo sham e por esse motivo não conseguimos calcular a expressão relativa do grupo periodontite (Tabela 1). Para responder a essa questão, tratamos ratos com Fenofibrato (comercialmente conhecido como Lipanon, FARMASA, BR), um agonista PPAR- $\alpha$. Na Figura 7, observamos que o tratamento com Lipanon (em doses comumente utilizadas em modelos animais de hiperlipidemia) [Ornalan at al., 2009; Syversen et al., 2009) causou aumento de perda óssea nos grupos de animais tratados. Podemos afirmar que a ativação do PPAR- $\alpha$ contribui para o aumento da perda óssea alveolar decorrente da periodontite devido, provavelmente, a perda de especificidade da rosiglitazona. O trabalho de Still et al., (2008) demonstrou que, em cultura de células, agonistas de PPAR- $\alpha$ e PPAR- $\beta$ (diluido em DMSO 10\%) induz a diferenciação de osteoblastos e formação óssea. A diferença nos resultados, provavelmente, está ligado ao uso do DMSO 10\% como veículo e ao nosso estudo ser realizado em animais. 0 agonista PPAR- $\beta$ não foi utilizado por ser uma droga cara e de difícil acesso no mercado. 


\section{CONCLUSÃO}

Com base nos resultados mostrados, podemos sugerir que o tratamento com rosiglitazona, independente da via de administração, agravou a perda óssea secundária à periodontite, analisada sete dias após a indução da doença. Esse agravamento é provavelmente devido ao aumento da expressão iNOS, RANKL e TRAF6 (relacionados a atividade de osteoclastos), e diminuição da expressão de Osterix (atividade de osteoblastos).

Como discutido acima, as discrepâncias com os resultados publicados por outros autores podem ser devidas à interferência do DMSO na composição do tratamento, o qual foi evidenciado neste estudo pelos diferentes mecanismos de sinalização observados para cada uma das vias de administração que utilizamos. 


\section{REFERÊNCIAS}

Arana V, Katchburian E. Histologia e embriologia oral. 2a ed. Rio de Janeiro: Guanabara Koogan; 2004, 372p.

Becker S, Dussus L, Kaaks R. Obesity related hyperinsulinaemia and hyperglycaemia and cancer development. Arch Physiol Biochem. 2009;115: 86-96.

Berger J, Moller DE. The mechanisms of action of PPARS. Rev, Med. 2002;53:409-35.

Bhaskar SN. Histologia e embriologia oral de orban. 9a ed. São Paulo: Artes Médicas; 1989. 501p.

Bose R, Sutherland GR, Pinsky C. Biological and methodological implications of prostaglandin involvement in mouse brain lipid peroxidation measurements. Neurochem Res. 1989;14: 217-20.

Bradley PP, Priebat DA, Christensen RD, Rothstein G. Measurement of cutaneous inflammation: estimation of neutrophil content with an enzyme marker. J Invest Dermatol.1982;78:206-9.

Bricola AA, Teixeira SA, De Luca IM, Muscara MN, Abdala FM, Porto CS, Zanesco A, Antunes E, De Nucci G. Upregulation of muscarinic receptors by long-term nitric oxide inhibition in the rat ileum. Clin. Exp. Pharmacol. Physiol. 2003;30:168-73.

Buhlin K, Hultin M, Norderyd O, Persson L, Pockley AG, Rabe P, Klinge B, Gustafsson A.Risk factors for atherosclerosis in cases with severe periodontitis. J Clin Periodontol. 2009; 36;(7):541-9.

Burgermeister E, Seger R. PPARgamma and MEK interactions in cancer. PPAR Res. 2008;2008:309-469.

Carranza FA, Newman MG. Periodontia clínica. 9a. ed. Rio de Janeiro: Guanabara Koogan; 2004. 864p.

Crotti TN, Ahern MJ, Lange K, Weedon H, Coleman M, Roberts-Thomson PJ, Haynes DR,Smith MD. Variability of RANKL and osteoprotegerin staining in synovial tissue from patients with active rheumatoid arthritis: quantification using color video image analysis. J Rheumatol. 2003;30:2319-24.

Crotti TN, Smith MD, Findlay DM, Zreigat H, Ahern MJ, Weedon H, Hatzinikolous, Capone M, Holding C, Haynes DR. Factors regulating osteoclast formation in human tissues adjacent to peri-implant bone loss: expression of receptor activator NFkappaB, RANK ligand and osteoprotegerin. Biomaterials. 2004;25:565-73.

Crotti TN, Smith MD, Weedon H, Ahern MJ, Findlay DM, Kraan M, Tak PP, Haynes DR. Receptor activator NF-kappaB ligand (RANKL) expression in synovial tissue from patients with rheumatoid arthritis, spondyloarthropathy, osteoarthritis, and from normal patients: semiquantitative and quantitative analysis. Ann Rheum Dis. 2002;61:1047-54.

McGuire DK, Inzucchi SE. New drugs for the treatment of diabetes mellitus part i: thiazolidinediones and their evolving cardiovascular implications. Circulation. 2010;117:440-9.

De Pommereau V, Dargent-Pare C, Robert JJ, Brion M. Periodontal status in insulindependent diabetic adolescents. J Clin Periodontol 1992;19:628-32.

De Pablo P, Chapple IL, Buckley CD, Dietrich T. Periodontitis in systemic rheumatic diseases. Nat Rev Rheumatol. 2009;54: 218-24.

De acordo com: International Committee of Medical Journal Editors. Uniform requiriments for manuscripts submitted to Biomedical Journal: sample references. Available from: http://www.icmje.org [2007 May 22]. 
Diab A, Deng C, Smith JD, Hussain RZ, Phanavanh B, Luvett-Racke AE, Drew PD, Racke MK. Peroxisome proliferatoractivated receptor agonist 15 Deox- $\Delta^{12}$, 14-prostaglandin $\mathrm{J}_{2}$ ameliorates experimental autoimmune encephalomyelitis. J. Immunol. 2002;168:2508-15.

Di Paola R, Mazzon E, Maiere D, Zito D,Britti D, De Majo M, Genovese T,Cuzzocrea S. Rosiglitazone reduces the evolution of experimental periodontitis in the rat. J Dent Res. 2007:85:156-61.

Dubreful L, Bascones A. Infecciones periodontales: papel de los anaerobios estrictos, importancia de las beta lactamasas, elección de um antibiotico. Rev Soc Odontol Plata. 1995;8:21-34.

Ducy P, Starbuck M, Priemel M, Shen J, Pinero G, Geoffroy V, Amling M, Karsenty G. A Cbfa1-dependent genetic pathway controls bone formation beyond embryonic development. Genes Dev. 1999;15:1025-36.

Elstner E, Muller C, Koshizuka K, Williamson EA, Park D, Asou H, Shintaku P, Said JW, Heber D, Koeffler HP. Ligands for peroxisome proliferator-activate receptor gamma and retinoic acid receptor inhibit growth and induce apoptosis. Proc Natl Acad Sci U.S.A. 1998;15:123-131.

Figueiredo MC, Parra SLN. Aspectos normais da membrana periodontal e osso alveolar. Site: www of human breast cancer cells in vitro and in BNX mice. Med, Scienc. 2002;95:8806-11.

Emrich LJ, Shlossman M, Genco RJ. Periodontal disease in non-insulin-dependent diabetes mellitus. J Periodontol. 1991;62:123.

Flier JS. Insulin receptors and insulin resistance. Annu Rev Med. 1983;34:45-160.

Galbraith GM, Hagan C, Steed RB, Sanders JJ, Javed T. Cytokine production by oral and peripheral blood neutrophils in adult periodontitis. J Periodontol.1997;68:832-8.

Genco RJ, Cohen DW, Goldman HM. Periodontia contemporânea. 1a. ed. São Paulo: Livraria Santos; 1996. 726p.

Grossi SG, Skrepcinski FB, Decaro T. Treatment of periodontal disease in diabetics reduces glycated hemoglobin. J Periodontol. 1997;68:713-9.

Hallgren R, Lundquist G. Elevated serum levels of pancreatic polypeptide are related to impaired glucose handling in inflammatory states. Scand J Gastroenterol. 1983;18:561-4.

Han S, Sidell N, fisher PB, Roman J. Up-regulation of p21 gene expression by peroxisome proliferator-activated receptor $-\gamma$ in human lung carcinoma cells. Clin Cancer Res. 2004;10:1911-19.

Haynes DR, Berg E, Crtti TN, Holding C, Weedon H, Atkins GJ, Zannetino A, Ahern MJ, Coleman M, Roberts-Thomson PJ, Kraan M, Tak PP, Smith MD. Osteoprotegerin expression in synovial tissue from patients with rheumatoid arthritis, spondyloarthropathies and osteoarthritis and normal controls. Rheumatology. 2003;43:1-12.

Haynes DR. Bone lysis and inflammation. Inflamm. Res. 2004;53:596-600.

He TC, Chan TA, Vogelstein B, Kinzler KW. PPAR- $\delta$ Is an APC-regulated target of nonsteroidal anti-inflammatory drugs. Cell. 1999;99:335-45. 
Heasman P, Collins J, Offenbacher S. Changes in crevicular fluid levels of interleukin-1b, leukotreine B4, prostaglandin E2, thromboxane B2, and tumor necrotic factor a in experimental gingivitis in humans. J Periodontol Res. 1993;28:241-7.

Herrera BS, Martins-Porto R, Campi P, Holzhausen M, Teixeira SA,Mendes GD, Costa SK, Gyurko R, Van Dyke TE, Spolidório LC, Muscará MN. Local and cardiorenal effects of periodontitis in nitric oxide-deficient hypertensive rats. Arch Oral Biol. 2010;56:41-7.

Herrera BS, Martins-Porto R, Maia-Dantas A, Campi P, Spolidório LC, Costa SK, Van Dyke TE, Gyurko R Muscará MN. "iNOS-derived nitric oxide stimulates osteoclast activity and alveolar bone loss in ligature-induced periodontitis in rats". J Periodontol. 2011 [Epub ahead of print].

Herzberg MC, Meyer MW, Kiliç A, Tao L. Host-pathogen interactions in bacterial endocarditis: streptococcal virulence in the host. Adv Dent Res. 1998;11:69-74.

Hirose M, Ishihara K, Saito A, Nakagawa T, Yamada S, Okuda K. Expression of cytokines and inducible nitric oxide synthase in inflamed gingival tissue. J Periodontol. 2001;72:590-7.

Hiroshi K, Toru A, Masayuki Y, Shinsuke O, Naoshi O, Ung-il C, Naoto K, Yasuo T, Takashi K Kozo N. Distinct effects of PPAR insufficiency on bone marrow cells, osteoblasts, and osteoclastic cells. J. Bone Miner Metab. 2005;23:275-79.

Holzhausen M, Garcia DF, Pepato MT, Marcantonio JE. The influence of short-term diabetes mellitus and insulin therapy on alveolar bone loss in rats. J Periodontal Res. 2004;39:188-93.

Holzhausen M, Rossa Júnior C, Marcantonio Júnior E, Nassar PO, Spolidório DM, Spolidório LC. Effect of selective cyclooxygenase-2 inhibition on the development of ligature-induced periodontitis in rats. J Periodontol. 2002;73:1030-6.

Joshipura KJ, Rimm EB, Douglass CW, Trichopoulos D, Ascherio A, Willett WC. Poor oral health and coronary heart disease. J Dent Res. 1996;75:1631-6.

Kawahito Y, Kondo M, Tsubouchi Y, Hashiramoto A, Bishop-Bailey D, Inoue K, Kohno M, Yamada R, Hla T, Sano H). 15deoxy-D 12,14 -PGJ2 induces synoviocyte apoptosis and suppresses adjuvant-induced arthritis in rats. J. Clin. Invest. 2000;106:189-97.

Karsenty G. Transcriptional control of skeletogenesis. Annu Rev Genomics Hum Genet. 2008:9:183-96.

Kato Y, Koide N, Komatsu T, Tumurkhuu G, Dagvado J, Kato K, Yokochi T. Metformin attenuates production of nitric oxide in response to lipopolysaccharide by inhibiting myd88-independent pathway. Arch physiol biochem. 2009;115:86-92.

Kendall HK, Marshall RI, Bartold PM. Nitric oxide and tissue destruction. Oral Dis. 2001;7:2-10.

Kenny S, Aubert R, Geiss L. Prevalence and incidence of non-insulin-dependent diabetes. NIH Publication.1995;95-1468.

Kersten S, Desvergne B, Wahli W. Roles of PPARs in health and disease. Nature. 2000;405: 421-4.

Kliewer SA, Xu HE, Lambert MH, Willson TM. Peroxisome proliferator-activated receptors: from genes to physiology. Recent Prog Horm Res. 2001;56:239-63. 
Lacey DL, Timms E, Tan HL, Kelley MJ, Dunstan CR, Burgess T,Elliott R, Colombero A, Elliot G, Scully S, Hsu H,Sullivan J, Hawkins N, Davy E, Capparelli C, Eli A, Qian YX, Kaufman S, Sarosi L, Shalhoub V, Senaldi G, Guo J,Delanney J, Boyle WJ. Osteoprotegerin ligand is a cytokine that regulates osteoclast differentiation and activation. Cell. 1998;93:165-76.

Laemmli UK. Cleavage of structural proteins during the assembly of the head of bacteriophage T4. Nature.1970;227:680-5.

Lalla E, Lamster IB, Drury S, Fu C, Schmidt AM. Hyperglycemia, glycoxidation and receptor for advanced glycation end products: potential mechanisms underlying diabetic complications, including diabetes-associated periodontitis. Periodontol. 2000;23:50-62.

Lee $\mathrm{CH}$, Chawla A, Urbiztondo N, Liao D, Boisvert WA, Evans RM. Atherogenic in ammation:modulation by ppar delta. Science. 2003;302:453-4.

Lee YH, Lee NH, Bhattarai G, Yun JS, Kim TI, Jee EC, Yi HK. PPARgamma inhibits inflammatory reaction in oxidative stress induced human diploid fibloblast. Cell Biochem Funct. 2010;28:490-6.

Lidstrom, JM. The effect of PPAR-gamma agonist on lung cancer and their relationship to the NF-Kappa B pathway. Tese de mestrado, Faculty of the College of Arts and Sciences of American University, Washington DC, EUA;2005.

Lindhe J, Karring T, Lang NP. Tratado de periodontologia clínica e implantologia oral. 4a ed. Rio de Janeiro. Guanabara Koogan. 2005. 1013p.

Loesche WJ. Bacterial mediators in periodontal disease. Clin Infect Dis. 1993;16:203-10.

Lohinai Z, Stachlewitz R, Székely AD, Fehér E, Dézsi L, Szabó C. Evidence for the expression of cyclooxygenase-2 enzyme in periodontitis. Life Sci. 2001;70: 279-90.

Lundy FT, Linden GJ. Neuropeptides and neurogenis mechnisms in oral and periodontal inflammation. Crit Rev Oral Biol Med. 2004;15:82-98.

Mangelsdorf DJ, Thummel C, Beato M, Herrlich P, Schiitq G, Umesono K, Blumberg B, Kastner P, Mark M, Chambon P, Evan RM. The nuclear receptor superfamily:the second decade. Cell. 1995;83;835-39.

Martin TJ, Ng KW. Mechanisms by which cells of the osteoblast lineage control osteoclast formation and activity. J Cell Biochem. 1994;56:357-66.

Matthews DC. The relationship between diabetes and periodontal disease. J Can Dent Assoc Mar. 2002;68:161-4.

Mattila KJ, Valtonen VV, Nieminen M Huttunen JK. Dental infection and the risk of new coronary events: prospective study of patients with documented coronary artery disease. Clin. Infect Dis. 1995;20:588-92.

Mayerson AB, Hundal RS, Dufour S, Lebon V, Befroy D, Cline GW, Enocksson S, Inzucchi SE,Shulman GI, Petersen KF. The effects of rosiglitazone on insulin sensitivity, lipolysis, and hepatic and skeletal muscle triglyceride content in patients with type 2 diabetes. Diabetes. 51:797-802.

Mealey BL, Rose LF. Diabetes mellitus and inflammatory periodontal diseases. Curr Opin Endocriol Diabetes Obes. 2008; 15:135-41.

Mealey BL. Diabetes and periodontal disease: two sides of a coin. Compend Contin Educ Dent. 2000;21:943-6. 
Miyata T, Hori O, Zhang J, Yan SD, Ferran L, lida Y, Schmidt AM. The receptor for advanced glycation end products (RAGE) is a central mediator of the interaction of AGE beta 2 microglobulin with human mononuclear phagocytes via an oxidantsensitive pathway. J Clin Invest. 1996;98:1088-94.

Nakashima K, Zhou X, Kunkel G, Zhang Z, Deng JM. The novel zinc finger-containing transcription factor osterix is required for osteoblast differentiation and bone formation. Cell. 2002;108:17-29.

Oliver WR, Shenk JL, Snaith MR, Russell CS, Plunket KD, Bodkin NL, Lewis MC, Winegar DA, Sznaidman ML, Lambert MH, Xu HE, Sternbach DD, Kliewer SA, Hansen BC, Willson TM. A selective peroxisome proliferator-activated receptor $\delta$ agonist promotes reverse cholesterol transport. Proc Natl Acad Sci U.S.A. 2001;98:5306-11.

Opperman RV, Rösing CK. Periodontia ciência e clínica. 1ª ed, São Paulo: Artes Médicas;2001. 458p.

Paquette DW, Williams R. Modulation of host inflammatory mediators as treatment strategy for periodontal diseases. Periodontology. 2000;24:239-52.

Pepato MT, Migliorini RH, Goldberg AL, Kettelhut IC. Role of different proteolytic pathways in degradation of muscle protein from streptozotocin-diabetic rats. Am J Physiol Endocrinol Metab. 1996;271:E340-7.

Pfaffl MW. A new mathematical model for relative quantification in real-time RT-PCR. Nar. 2002;29: 45.

Pepato MT, Folgado VB, Kettelhut IC, Brunetti IL. Lack of anti-diabetic effect of Eugnia jambolona leaf decoction on rat streptozotocin diabetes. Braz J Med Biol Res. 2001;34:389-95.

Pinto VG. Levantamento epidemiológico em saúde bucal: Brasil, zona urbana. Brasília, Ministério da saúde,1996.[s.p]

Promsudthi A, Pimapansn S, Deerochanawong C, Kanchanavasita W). The effect of periodontal therapy on uncontrolled type 2 diabetes mellitus in older subjects. Oral Dis. 2005;11:293-8.

Quinn JM, Neale S, Fujikawa Y, McGee JO, Athanasou NA. Human osteoclast formation from blood monocytes, peritoneal macrophages, and bone marrow cells. Calcif Tissue Int.1998;62:527-31.

Ricote Huang J, Fajas L, Li A, Welch J, Najib J, Witztum J, Auwerx J, Palinsk W, Glass CK. Expression of the peroxisome proliferator-activated receptor (PPAR-g)in human atherosclerosis and regulation in macrophages y colony stimulating factors and oxidized low density lipoprotein. Med Sciences.1998;95:7614-9.

Rosen ED, Walkey CJ, Puigserver P, Spiegelman BM. Transcriptional regulation of adipogenesis. Genes Dev. 2000;14: 1293-307.

Saluja I, Granneman JG, Skoff RP. PPAR delta agonists stimulate oligodendrocyte differentiation in tissue culture. Glia. 2001;33:191-204.

Sarraf P, Mueller E, Smith WM, Wright HM, Kum JB, Aaltonen LA, Chapelle AL, Spiegelman BM. Loss-of-function mutations in ppar-g associated with human colon cancer. Molecular Cell. 1999;3:799-804.

Schmidt AM, Yan SD, Brett J, Mora R, Nowygrod R, Stern D. Regulation of human mononuclear phagocyte migration by cell surface-binding proteins for advanced glycation End Products. J. Clin. Invest. 1993;91:2155-68. 
Shembade N, Ma A, Harhaj EW. Inhibition of NF-kappaB signaling by A20 through disruption of ubiquitin enzyme complexes. Science. 2010;327:1135-9.

Socransky SS, Haffajee AD. The bacterial etiology destructive periodontal disease: current concepts. J. Periodontol. 1992;63:322-31.

Steppan CM, Lazar MA. The current biology of resistin. J Intern Med. 2004;255:439-47.

Stevens A, Lowe J. Histologia Humana. 2a . ed. Sāo Paulo: Manole, 2001. 408p.

Taanu DS. Association between cigarette smoking and periodontal health. Quintessence Int. 1997;28:535-9.

Takahashi N, Akatsu T, Udagawa N, Sasaki T, Yamaguchi A, Moseley JM, Martin TJ, suda T. Osteoblastic cells are involved in osteoclast formation. Endocrinology. 1998;123:2600-2.

Tan NS, Michalik L, Desvergne B, Wahli W. Multiple expression control mechanisms of peroxisome proliferator-activated receptors and their target genes. J S Biochem \& Mol Biol. 2005;93:99-105.

Tanner A, Maiden MF, Macuch PJ, Murray LL, Kent RL Jr. Microbiota of health, gingivitis, and initial periodontitis. J Clin Periodontol. 1998;25:85-98.

Taylor G, Burt B, Becker M. Non-insulin dependent diabetes mellitus and alveolar bone loss progression over 2 years. J Periodontol. 1998;69:76-83.

Teixeira SA, Castro GM, Papes F, Martins ML, Rogerio F, Langone F, Santos LM, Arruda P, De Nucci G, Muscará MN. Expression and activity of nitric oxide synthase isoforms in rat brain during the development of experimental allergic encephalomyelitis. Mol Brain Res. 2002;99:17-25.

Thorstensson $\mathrm{H}$, Hugoson A. Periodontal disease experience in adult long-duration insulin-dependent diabetics. $\mathrm{J}$ Clin Periodontol. 1993;20:352-8.

Udagawa N. The mechanism of osteoclast differentiation from macrophages: possible roles of $\mathrm{T}$ lymphocytes in osteoclastogenesis. J Bone Miner Metab. 2003;21:337-43.

Vettore MV, Leal M, Leão AT, Da Silva AM, Lamarca GA, Sheiham A. The relationship between periodontitis and preterm low birthweight.J Dent Res. 2008;87:73-8.

Wang D, Dubois RN. Therapeutic potential of peroxisome proliferator-activated receptors in chronic inflammation and colorectal cancer. Cell Biochem Funct. 2010;28:490-6.

Xu JW, Konttinen YT, Lassus J, Natah S, Ceponis A, Soloviera S, Aspenberg P, Santavirta S. Tumor necrosis factor-alpha (TNF-alpha) in loosening of total hip replacement (THR). Clin Exp Rheumatol. 1996;14:643-8.

Yamauchi T, Kadowaki T. The molecular mechanisms by which PPAR gamma/RXR inhibitors improve insulin resistance. Nippon Rinsho. 2001;59:2245-54. 
Yasuda H, Shima N, Nakagawa N, Yamaguchi M, kinosaki M, Mochizuki S, Tomoyasu A,Yano k, Goto M, Murakami A,Tsuda E, Morinaga T, Higashio k, Udagawa n, takahashi N, Suda T. Osteoclast differentiation factor is a ligand for osteoprotegerin/osteoclastogenesis-inhibitory factor and is identical to TRANCE/RANKL. Proc Natl acad Sci USA. 1998;95: 3597-602.

Zwerina J, Hayer S, Tohidast-Akrad M, Bergmeister H, Redlich K, Feige U, Dunstan C, Kollias G, Steiner G, Smolen J, Schett G. Single and combined inhibition of tumor necrosis factor, interleukin-1, and RANKL pathways in tumor necrosis factor-induced arthritis: effects on synovial inflammation, bone erosion, and cartilage destruction. Arthritis Rheum. 2004;50:277-90. 